\title{
LAS REPERCUSIONES DEL SISTEMA DE CORTE EN LOS CORREGIMIENTOS DE INDIOS DEL PERÚ VIRREINAL (1565-1600) ${ }^{1}$
}

\author{
Javier Enrique Robles Bocanegra \\ (Universidad Autónoma de Madrid) \\ javiere.robles@estudiante.uam.es
}

\section{RESUMEN}

La corte fue la organización política-social de la Monarquía Hispánica en la Edad Moderna. Este modelo se basó en la articulación de poder mediante relaciones personales. Así, las redes clientelares por lazos de amistad, parentesco, paisanaje y costumbres jugaron un papel medular para la concesión de mercedes del monarca a sus servidores. Esto permitió la integración de los reinos y sus élites en la monarquía. En ese sentido, el artículo analiza los aspectos del sistema cortesano que tuvieron repercusión en los Andes del virreinato peruano a través de los corregimientos de indios. Para ello, se examinan las calidades políticas que tuvo el corregidor como magistrado del rey, así como las mediaciones personales que estableció con sus criados domésticos, ministros de gobierno y élites indígenas. Esto determinará los rasgos comunes y diferentes que tuvo su entorno con la corte regia.

PALABRAS CLAVE: Corte; mediaciones personales; corregidor de indios; príncipe; élites indígenas.

\section{THE REPERCUSSIONS OF THE COURT SYSTEM IN THE CORREGIMIENTOS OF INDIANS OF THE VICEREGAL PERU (1565- 1600)}

\begin{abstract}
The court was the political-social organization of the Hispanic Monarchy in the Modern Age. This model was based on the articulation of power through personal relationships. Thus, patronage networks by ties of friendship, kinship, peasantry and customs played a key role in granting mercedes of the monarch or prince to his servants. This allowed the integration of the kingdoms and their elites in the monarchy.

\footnotetext{
${ }^{1}$ Una versión de este trabajo fue presentado como ponencia en el XII Seminario Internacional "La Corte en Europa": "Los primeros imperios mundiales: España y Portugal en contraste", celebrado en Madrid los días 24 y 25 de octubre del 2018. Asimismo, el estudio corresponde a una versión resumida de mi Trabajo de Fin de Máster en Historia Moderna, leída el 6 de julio del 2018. Agradezco a mi director de trabajo, José Martínez Millán, y a los profesores Manuel Rivero, Carlos de Carlos Morales y Antonio Álvarez-Ossorio por sus sugerencias y comentarios, que hicieron posible la máxima calificación del Tribunal.
} 
In this sense, the article analyzes the aspects of the court system that had repercussion in the Andes of the Peruvian viceroyalty through the corregimientos of Indians. To this end, we examine the political qualities that the corregidor had as magistrate of the king, as well as the personal mediations that he established with his domestic servants, government ministers and indigenous elites. This will determine the common and different features that his environment had with the royal court.

KEY WORDS: Court; personal mediations; corregidor de Indians; prince; indigenous elites.

$* * *$

\section{INTRODUCCIÓN}

Los estudios sobre los corregidores de indios en la América hispánica han dado un viraje renovador. Estos han pasado de los enfoques tradicionales de índole institucional o económico-social ${ }^{2}$ a los mecanismos de cultura política que poseyó la

\footnotetext{
${ }^{2}$ El enfoque institucionalista ha analizado las características de la actuación del oficial regio dentro de la legislación (ordenanzas y provisiones) que el virrey le mandaba. Así, ha resaltado que el magistrado tenía la plena jurisdicción civil y criminal en su provincia y que era solo representante del rey. Véase en Carlos Castañeda, "The Corregidor in Spanish Colonial Administration”, The Hispanic American Historical Review 9(4) (1929): 446-470; Fernando Albi, El corregidor en el municipio español bajo la monarquía absoluta (Madrid: Instituto de Estudios de Administración Local, 1943); Guillermo Lohmann, El Corregidor de indios en el Perú bajo los Austrias (Lima: Pontificia Universidad Católica del Perú, 2001); Beatriz Suñe, "El corregidor del valle de Guatemala: una institución española para el control de la población indígena," Revista de la Universidad Complutense 117 (1979): 153-168. Otro eje temático dentro del enfoque institucionalista ha sido el análisis comparativo entre la legislación que poseyó el corregidor y las otras autoridades reales locales como el gobernador y el alcalde mayor. Véase en Carlos Molina, "Gobernaciones, alcaldías mayores y corregimientos en el reino de Guatemala," Anuario de Estudios Americanos 17 (1958):105-132; Alfonso García-Gallo, “Alcaldes mayores y corregidores en Indias," en Estudios de Historia del Derecho Indiano (Madrid: Instituto Nacional de Estudios Jurídicos, 1972), 714-736. En segundo lugar, la perspectiva económico-social analizó el desenvolvimiento político del corregidor para conseguir beneficios lucrativos a través de la recolección del tributo, reparto de los indios mitayos, producción textil y en el reparto de mercancías a los indios. Véase los estudios de K. Andrien, "El corregidor de indios, la corrupción y el Estado virreinal en el Perú (1580-1630)," Revista de Historia Económica 4(3) (1986): 493-520; Noble D. Cook, "The Corregidores of the Colca Valley, Peru: Imperial Administration in an Andean Region," Anuario de Estudios Americanos 60(2) (2003): 413-439; Carlos Lazo y Javier Tord, "Economía y Sociedad en el Perú Colonial (Movimiento social),"en Historia del Perú (Lima: Juan Mejía Baca, vol. V, 1980), 39-50; Javier Tord, "El corregidor de indios del Perú: comercio y tributos," Historia y Cultura 8 (1974): 173-207; Alfredo Moreno, El corregidor de indios y la economía peruana del siglo XVIII (Los repartos forzosos de mercancías) (Madrid: Consejo Superior de Investigaciones Científicas, 1977). Otra variante en el enfoque social está en el análisis del corregidor como agente del rey para la construcción del "Estado colonial" en las ciudades del Perú virreinal o también como agentes de la desestructuración del poder étnico en los curacazgos andinos al encuadrarlos en el marco político de la
} 
calidad regia del oficio a fin de interpretar cómo el magistrado legitimó su poder real en su provincia. Los trabajos han remarcado que el corregidor de indios no solo fue mero ejecutor de las ordenanzas del virrey, sino que fue la efigie del rey en las sociedades indígenas, es decir, la personificación o representación viva del monarca en la jurisdicción ${ }^{3}$. Esto fue posible gracias a la cultura política que practicó el corregidor en sus discursos, presentación de sus atributos de la majestad real (título, tratamiento y vara de justicia), las ceremonias de juramento, rituales de provisión real al inicio de la litigación y el impulso de las redes de patronazgo con los curacas principales e indios principales.

Dicho aporte historiográfico nos sirve para bosquejar las repercusiones del modelo cortesano en los corregimientos de los Andes del Perú virreinal. La pregunta clave sería qué elementos de la corte regia fueron comunes con el entorno del corregidor de indios. Su esfera de poder estaba conformada por los servidores domésticos de su casa y el grupo de ministros que lo asistían en el gobierno de su provincia (teniente mayor, tenientes de repartimientos, escribanos, alguaciles e indios intérpretes). De este modo, el artículo se centra en analizar las influencias del sistema cortesano en la práctica política de los corregidores de indios por medio de tres factores: la naturaleza política de su oficio regio, las tipologías de redes de patronazgo establecidas para el nombramiento de oficios y las mediaciones personales con las élites indígenas para su integración en la monarquía ${ }^{4}$. Por tanto, se podrá comprender cómo la Monarquía Hispánica articuló su poder en los Andes desde la corte.

Corona. Véase en Carlos S. Assadourian, "Los señores étnicos y los corregidores de indios," en Transiciones hacia el sistema colonial andino (Lima: El Colegio de México, 1994), 244-260; Adolfo Polo, "El corregidor de Cusco y el Estado colonial. Siglos XVI-XVII”, (Tesis de Maestría en Historia, Pontificia Universidad Católica del Perú, 2010).

${ }^{3} \mathrm{El}$ jurista castellano Jerónimo Castillo de Bobadilla fue el que utilizó por primera vez el concepto de "efigie del rey" para los corregidores del siglo XVI, señalando que a dichos oficiales reales les correspondían los mismos atributos, privilegios, preeminencias y dignidades del monarca por ser príncipes y cabezas de sus ciudades. Véase en J. Castillo de Bobadilla, Política para corregidores, y señores de vasallos, en tiempo de paz, y de guerra, y prelados en lo espiritual, y temporal (Madrid: Imprenta de Joaquín de Ibarra, 1759 [1597]), Lib. III, Cap. II, 15. Para la aplicación del concepto al caso peruano, véase mi estudio en Javier Robles, "La efigie del rey en el corregidor de indios: cultura política y poder real de un magistrado en el proceso de consolidación del Estado virreinal durante el régimen del gobernador Lope García de Castro, Perú 1564-1569", (Tesis de Licenciatura en Historia, Universidad Nacional Mayor de San Marcos, 2015). Dicho estudio se basó en el análisis de expedientes de pleitos judiciales que los corregidores de indios celebraron en el quinquenio de García de Castro. En las litigaciones, los magistrados exhibían y mostraban un lenguaje y simbología ritual en sus dignidades, tratamientos y prácticas políticas, que eran reconocidos por las sociedades indígenas. Estos mecanismos de poder hicieron que los corregidores se presentasen ante las élites e indios comunes como la personificación del monarca en su jurisdicción, ya que asimilaban los mismos comportamientos de cultura cortesana que el rey poseía. Para una construcción detallada del concepto en el contexto de la América hispánica en los siglos XVI y XVII, véase las págs. 21-24.

${ }^{4}$ Los procesos de negociación de los curacas con las autoridades reales y eclesiásticas solo han sido estudiados desde la etnohistoria y la historia del Derecho. La primera perspectiva se ha caracterizado por presentar la organización y gobierno de las guarangas (comunidades de mil indios) como mecanismos políticos para que los curacas estableciesen entramados de poder con el encomendero, doctrinero y corregidor a fin de alcanzar beneficios para sus comunidades o para su movilidad social. 
Para responder adecuadamente a estas interrogantes, el trabajo sigue las pautas conceptuales de la corte propuestas en los últimos años por el profesor José Martínez Millán. Una primera idea consiste en definir la corte como una organización políticasocial donde el monarca articulaba el poder por todos los reinos de la monarquía mediante relaciones de poder no institucionales ${ }^{5}$. Estos vínculos se dieron no desde acuerdos contractuales sino por mediaciones personales ${ }^{6}$. Por lo tanto, un segundo concepto definiría a la corte como el punto de encuentro entre gobernantes y gobernados, ya que su organización asoció a tres grandes áreas que giraban en torno del rey o príncipe: las instituciones de gobierno (magistrados, ministros y oficiales reales), casa real (familia real) y el grupo heterogéneo de cortesanos ${ }^{7}$, quienes eran los pretensores que acudían a la corte en pos de favores, negocios o mercedes ${ }^{8}$. Los conceptos encontraron relación con el Diccionario de Autoridades, que definió a la corte como el «conjunto o cuerpo de todos los consejos, tribunales superiores, ministros, criados y oficiales de la casa real, y otras personas que asisten y sirven a las Personas Reales, cuya cabeza es el rey o príncipe soberano» ${ }^{9}$. De ahí que se considerase al carácter principesco como el principio fundamental que presentaba la corte. Su estructura debía de tener una preeminencia jerárquica, quien era detentada por uno o varios señores a los que se les reconocía capacidad de mando y dominio sobre las otras personas del grupo ${ }^{10}$. Un virrey en la América hispánica detentaba dicha calidad de príncipe, además de ser el alter ego del rey. Lo mismo puede aplicarse para la corte de un gobernador, de un duque o de un obispo, puesto que en ellos recaía la suprema potestad de sus jurisdicciones. Por tal razón, el profesor Manuel Rivero afirmó que la

Véase los estudios de Marina Zuloaga, La conquista negociada: guarangas, autoridades locales e imperio en Huaylas, Perú (1532-1610) (Lima: Instituto Francés de Estudios Andinos, Instituto de Estudios Peruanos, 2012); Karoline Noack, "El orden colonial inventado: estrategias y actitudes de los caciques e indígenas de Cajamarca, sierra norte del Perú, S. XVI," Cuadernos de Historia 1 (2002): 5-14; Karen Spalding, De indio a campesino. Cambios en la estructura social del Perú colonial (Lima: Instituto de Estudios Peruanos, 1974). La segunda perspectiva subrayó la asimilación de la legislación castellana en la cultura jurídica de los curacas a fin de legitimar sus pedidos de mercedes durante la litigación en la Real Audiencia o Consejo de Indias, utilizando todas las instancias del sistema de justicia del virreinato. Véase el estudio de José Carlos de la Puente, Andean cosmopolitans: seeking justice and reward at the Spanish royal court (Austin: University of Texas Press, 2018), cap. 2.

5 José Martínez Millán, "Introducción”, La Monarquía de Felipe II: la Casa del Rey (Madrid: Fundación Mapfre, vol. I., 2005), 17-21.

${ }^{6}$ José Martínez Millán, Instituciones y elites de poder en la Monarquía Hispana durante el siglo XVI (Madrid: Ediciones de la Universidad Autónoma de Madrid, 1992), 14-21; Gijs Versteengen, Corte y Estado en la historiografía liberal: un cambio de paradigma (Madrid: Polifemo, 2015), 61; José E. Hortal y Félix Labrador, La Casa de Borgoña: la Casa del rey de España (Leuven: Leuven University Press, 2014), 15.

7 Martínez Millán, "Introducción”, La Monarquía de Felipe II, 37; Manuel Rivero, "Court Studies in the Spanish World” En The Court in Europe, ed. M. Fantoni (Roma: Bulzoni Editore, 2012), 143.

${ }^{8}$ Versteegen, Corte y Estado, 61-62.

${ }^{9}$ Diccionario de la lengua castellana en que se explica el verdadero sentido de las voces, su naturaleza y calidad, con las phrases o modos de hablar, los proverbios o refranes, y otras cosas convenientes al uso de la lengua (Madrid: Imprenta de Francisco del Hierro, 1729), vol. 2., 628. Véase también en Antonio Álvarez-Ossorio, "Corte y cortesanos en la Monarquía de España", en Educare il corpo. Educare la parola: nella trattatisdica del Rinascimento, eds. G. Patrizi e A. Quondam (1997), 300.

10 Álvarez-Ossorio, "Corte y cortesanos en la Monarquía de España”, 303. 
corte no vendría a ser realmente un lugar geográfico sino un espacio virtual, dado que muchos ministros vivían lejos de la casa real; pero pertenecían a la corte porque eran criados del rey ${ }^{11}$. Además todos los súbditos que recibían la merced real pasaban a pertenecer a la extensa familia del rey, ya sea sirviéndole en los oficios domésticos, en los oficios de gobierno o en ambos al mismo tiempo. No existía una separación entre la esfera pública y privada ${ }^{12}$.

En ese sentido, ¿cómo pudieron repercutir estos conceptos cortesanos en las provincias del corregidor de indios del virreinato peruano? Las palabras del profesor José Martínez Millán nos arrojan algunas luces al precisar que «ante la imposibilidad de poder ejercer la jurisdicción, dado el número y extensión de los reinos, los monarcas crearon organismos en las ciudades a las que se les consideró parte de la corte, a pesar de la separación que existía con la persona real» ${ }^{13}$. Fue ese el caso de los corregidores, que fueron establecidos por los monarcas para controlar y dar mercedes reales en las ciudades y villas ${ }^{14}$. De esta forma, ellos utilizaron a los corregidores para hacerse presentes en el gobierno de las zonas más alejadas de sus reinos.

Tales pareceres metodológicos nos llevan a plantear como hipótesis que la corte regia repercutió en el entorno de los corregidores de indios a fin de hacer presente el gobierno del rey en las provincias andinas. Teniendo en cuenta que el magistrado personificaba al rey por medio de la concesión de mercedes que daba a sus allegados, se puede señalar rasgos comunes con la corte regia como la calidad del corregidor en ser la cabeza de su jurisdicción, la organización de oficios domésticos de su casa, la función de dicha casa como núcleo articulador de poder y la organización de sus ministros de gobierno. Pero al mismo tiempo, las repercusiones tendrían matices que cuestionarían la validez del modelo cortesano en los corregimientos, por lo que también se analizarán esas diferencias. Las fuentes primarias que sustentan el trabajo son los juicios de residencia contra los corregidores y relaciones de autoridades reales y eclesiásticas provenientes de repositorios peruanos y españoles.

\section{LA CREACIÓN DE LOS CORREGIMIENTOS DE INDIOS EN EL PERÚ VIRREINAL (1565)}

El reto de la Monarquía Hispánica para el gobierno de los Andes del virreinato peruano consistía en la creación de un magistrado provisto de facultades, prerrogativas, preeminencias y dignidades derivados de la majestad real, similares a los que tenían los virreyes. Estas calidades iban a permitir que dicha autoridad se presentase como la representación o personificación del monarca en la sociedad indígena, por lo que sería el encargado de articular el poder real en su respectiva jurisdicción ${ }^{15}$. Esta tarea fue

\footnotetext{
${ }^{11}$ Rivero, "Court Studies in the Spanish World", 145.

12 Martínez Millán, "Introducción", La Monarquia de Felipe II, 39; Álvarez-Ossorio, "Corte y cortesanos en la Monarquía de España", 301.

${ }^{13}$ Martínez Millán, "Introducción", La Monarquia de Felipe II, 37

14 Ibídem, 37-38.

${ }^{15}$ Javier Robles, "Dos aspectos claves en la política del virrey Marqués de Cañete. Autoridades y tasación en el ordenamiento de los indios, Perú 1555-1560," en Actas del I Congreso de Historia y Cultura,
} 
realizada por el licenciado Lope García Castro, consejero de Indias de vasta trayectoria jurídica, quien en 1563 fue nombrado por Felipe II como gobernador del Perú y presidente de la Real Audiencia de Lima ${ }^{16}$. Como mandato central, García de Castro recibió la orden de «enseñarles a los indios a vivir políticamente» ${ }^{17}$. Esto significó que los repartimientos indígenas tenían que agruparse en provincias a fin de garantizar su unidad política-administrativa ${ }^{18}$. Estas circunscripciones bajo el liderazgo de un magistrado eran necesarias porque él promovería el ordenamiento de los pueblos de indios.

De esta manera, el gobernador creó a un corregidor específicamente para los repartimientos de indios, que fueron demarcaciones compuestas por una o más comunidades indígenas. Así lo expresó García de Castro en 1565 al precisar que había dividido a los indios en provincias, donde el corregidor libraría todos los negocios políticos y jurídicos ${ }^{19}$. Este parecer se aplicó en las provisiones que el gobernador dio a sus primeros corregidores de indios, Pedro Mejía y Juan de la Reinaga, en las provincias del Collao y Jauja respectivamente. Él les encomendó que unificasen a los pueblos indígenas, señalándoles los repartimientos que integraban sus jurisdicciones ${ }^{20}$. Esta medida reflejó la asimilación de las sociedades indígenas dentro de la organización política de la monarquía, que les permitiría regirse cada vez más con mayor autonomía ${ }^{21}$.

\section{EL CORREGIDOR DE INDIOS, CABEZA DE SU PROVINCIA}

La administración de una jurisdicción conferida al corregidor de indios reflejó un rasgo común con la corte: la dignidad de ser primera potestad. Dicho magistrado era la cabeza de su provincia. En 1568, el gobernador García de Castro plasmó la potestad en la provisión que entregó al corregidor de indios de Chicama y Pacasmayo, Antonio de Morales, al presentarlo como «la cabeza de su provincia y de sus términos en nombre de Su Majestad» ${ }^{22}$. Esto significó que el magistrado gozaba de la preeminencia jerárquica sobre todos los individuos que habitaban su provincia ${ }^{23}$. Se les

eds. E. Rosario, C. Castillo y M. Palacios (Lima: Seminario de Historia Rural Andina, Universidad Nacional Mayor de San Marcos, 2014), 10-11; Robles, "La efigie del rey en el corregidor de indios," 24.

16 AGI, Lima, 569, L. 11, f. 1r-v., Provisión y título de presidencia de la Audiencia de Lima al licenciado García de Castro, Madrid, 16-VIII-1563.

17 AGI, Lima, 569, L. 11, f. 25v-26r., Instrucción al licenciado García de Castro para nuevas poblaciones, Madrid, 16-VIII-1563. 232.

${ }^{18}$ Robles, "La efigie del rey en el corregidor de indios," 70-71; Lohmann, El Corregidor de indios, 231-

${ }^{19}$ Colección Gobernantes del Perú. Levillier (en adelante CGPL), III, p. 80, Correspondencia del licenciado García de Castro a Felipe II, Lima, 30-IV-1565; CGPL, III, p. 102, Correspondencia del licenciado García de Castro a Felipe II, Lima, 23-IX-1565.

${ }^{20}$ Colección Juicio de Límites entre Perú y Bolivia, I, pp. 75-76, Provisión del licenciado García de Castro al corregidor de indios del Collao, Lima, 23-VI-1565; BNE, Mss. 3043: Instrucción del licenciado García de Castro al corregidor de indios de Janja, Lima, 27-VI-1565, f. 1r.

${ }^{21}$ Lohmann, El Corregidor de indios, 88.

${ }^{22}$ Libro de Cabildo de Trujillo, II, p. 146, Acta del Cabildo de Trujillo, Presentación de la provisión del licenciado García de Castro al corregidor de Chicama y Pacasmayo, Trujillo, 28-XII-1568.

${ }^{23}$ Robles, "La efigie del rey en el corregidor de indios," 91-92. 
dotó del mando político sobre los españoles, curacas, indios principales e indios comunes que residían en la jurisdicción ${ }^{24}$.

Este privilegio se caracterizó por la posesión del mero y mixto imperio en su circunscripción ${ }^{25}$, es decir, el corregidor concentró la potestad de ser justicia mayor al administrar la jurisdicción civil y criminal $^{26}$. Al mismo tiempo se encargaba de la gobernación en cualquier negocio político. Estas facultades fueron precisadas por el licenciado García de Castro al señalar que todos los negocios que existiesen entre los indios y entre indios con españoles serían llevados por el corregidor ${ }^{27}$. Asimismo, llevaron la tarea de supervisar la labor de los curacas, encomenderos y doctrineros. Este hecho fue resaltado por el licenciado en 1569 al indicar que un magistrado logró impedir que los encomenderos y curacas se llevasen más de 30.000 pesos de la recolección de tributos ${ }^{28}$. Estas medidas hicieron que García de Castro señalase al corregidor de indios como la fuente de garantía para que el rey supiese todo lo que pasaba en el Perú ${ }^{29}$. En ese sentido, son adecuadas las afirmaciones de José Mariluz Urquijo al manifestar que el magistrado «tiene la potestad del rey para nombrar, remover y fijar la competencia de cada oficial». Él tenía que ver «de qué modo reemplazar al monarca en las tareas que no puede cumplir personalmente» ${ }^{30}$. En consecuencia, el mero y mixto imperio hacía que el corregidor reprodujese en su territorio lo que el rey simbolizó, ya que poseía un ministerio universal donde ninguna materia le estaba vedada ${ }^{31}$. Por lo tanto, era el depositario general de la suprema potestad regia en su provincia ${ }^{32}$.

Tales razones llevaron a que la literatura política de la Edad Moderna considerase al corregidor como una especie de príncipe en su jurisdicción. Esto fue reflejado por Jerónimo Castillo de Bobadilla, quien aseveró que el «corregidor es príncipe de su ciudad y provincia que gobierna» ${ }^{33}$. Según el jurista, dicho título principesco merecía estar en el magistrado porque él poseía «el mayor imperio y mando después del rey, y jurisdicción para conocer de todos los negocios» ${ }^{34}$. Su fundamento

${ }^{24}$ CGPL, III, p. 70, Correspondencia del licenciado García de Castro al Consejo de Indias, Lima, 26-IV-1565.

${ }^{25}$ Castillo de Bobadilla, Política para corregidores, Lib. I, Cap. II, 21.

${ }^{26}$ Juan Hevia, Curia Philipica (Madrid: Oficina de Ramón Ruíz, 1797), 19; Enrique Ruiz Guiñazú, La magistratura indiana (Buenos Aires: Universidad de Buenos Aires, 1916), 292-293.

${ }_{27}$ CGPL, III, p. 70, Correspondencia del licenciado García de Castro al Consejo de Indias, Lima, 26-IV-1565.

28 AGI, Lima, 270, f. 3v., Correspondencia del licenciado García de Castro al Consejo de Indias, Lima, 27-IV-1569.

${ }^{29}$ CGPL, III, p. 146, Correspondencia del licenciado García de Castro al Consejo de Indias, Lima, 12-I-1566.

30 José Mariluz Urquijo, El agente de la administración pública en Indias (Buenos Aires: Instituto Internacional de Historia del Derecho Indiano, 1998), 65

31 Albi, El corregidor en el municipio español, 85; Castañeda, "The Corregidor in Spanish Colonial Administration," 450.

${ }^{32}$ Lohmann, El Corregidor de indios, 180; Molina, "Gobernaciones, alcaldías mayores y corregimientos," 126.

${ }^{33}$ Castillo de Bobadilla, Politica para corregidores, Lib. III, Cap. II, 15.

34 Ibídem, 16. 
radicó en que dicha autoridad tenía el primer lugar después del rey. Sin embargo, la calidad de príncipe no se asimiló tanto a la dignidad del magistrado. Primero, el corregidor de indios no tenía una suprema potestad en su administración. Si bien es cierto que era señor y justicia mayor en su provincia al estar por encima de los alcaldes indígenas, sus decisiones judiciales podían ser apelables ante el corregidor de la ciudad. Sus fallos podían ser rebatidos y no eran del todo supremos. Segundo, su poder político estaba limitado por ordenanzas e instrucciones que les mandaban los virreyes o gobernadores. Sus facultades terminaban cuando podían opacar las disposiciones reales. Esto reflejó que el corregidor no tenía libertad para innovar o sugerir determinaciones en la legislación indiana. Su dominio y mando político como cabeza de la provincia descansaba en ejecutar y hacer cumplir las normas. Por lo tanto, el corregidor de indios actuó como una autoridad delegada en nombre del rey. Estas cuestiones hicieron que el carácter principesco no estuviese plenamente en la calidad de su oficio y marcaron una diferencia importante con la corte.

Una segunda característica común con la corte fue que el corregidor de indios - al ser cabeza de su jurisdicción - se legitimó como pater familias, es decir, era el encargado de conceder las mercedes del rey a sus servidores que lo asistían en el gobierno de su provincia. En 1566, el gobernador García de Castro aseveró dicha naturaleza política en el magistrado subrayando que «cuanto convenía para descargo de la real conciencia que haya corregidores entre los indios» ${ }^{35}$. Aquel parecer reflejaba que el corregidor tenía que hacer entrega de la grandeza del monarca en cada uno de los súbditos. Esto fue entendido por la literatura política de la Edad Moderna como la distribución de la majestad real por medio de la concesión de mercedes que emanaban del rey. Así lo manifestó el jurista Bartolomé Góngora al resaltar que la severidad real del corregidor se daba «porque en los oficios entrega la honra de las dos majestades» ${ }^{36}$. Esto fue ratificado por Lorenzo de Guardiola, quien precisó que el corregidor hacía buena gobernación cuando «amparaba los súbditos en el bien y los libraba del mal, y daba a cada uno lo que merecía, y lo que es suyo» ${ }^{37}$. Así, dicha autoridad se concebía como el padre de su república, en el sentido de que daba las honras reales a cada uno según sus merecimientos y distinciones. De este modo, se presentó al corregidor de indios como el pater familias de su provincia. El cronista Felipe Guamán Poma compartió dicho pensamiento y resaltó que el corregidor tenía que honrar, principalmente, a los curacas principales, indios principales, indios comunes, alcaldes y escribanos que le sirviesen porque así lo mandaba la majestad real ${ }^{38}$. El corregidor aparecía como el prototipo de justicia, que otorgaría merced y protección a cambio de

35 CGPL, III, p. 199, Correspondencia del licenciado García de Castro a Felipe II, Lima, 1-X-1566; CGPL, III, p. 159; Correspondencia del licenciado García de Castro al Consejo de Indias, Lima, 26-II1566

36 Bartolomé Góngora, El corregidor sagaz: abisos, y documentos morales para los que lo fueren (Sevilla: Sociedad de Bibliófilos Españoles, 1960[1656]), 116. 4.

${ }^{37}$ Lorenzo de Guardiola, El Corregidor perfecto y Juez (Madrid: Imprenta y Librería de López, 1785), 3-

38 Felipe Guamán Poma de Ayala, Nueva corónica y buen gobierno (México: Fondo de Cultura Económica, 1993), 39. 
servicio $^{39}$. Por consiguiente, su ejercicio garantizaba que el rey fuese señor enteramente de todas las provincias del virreinato peruano ${ }^{40}$. Su implementación fue vista por García de Castro como un proyecto de extensión de las relaciones políticas y sociales de Felipe II en los Andes ${ }^{41}$.

No obstante, la consideración del corregidor como padre de su provincia tendría ciertas diferencias con el modelo cortesano. Si dicho magistrado no tenía un pleno poder principesco, las mercedes reales que daba se ajustaban a las disposiciones legislativas del monarca o virrey. Esto quiere decir que el corregidor no podía ejercer la entrega de cualquier merced o favor a sus allegados. Las ordenanzas y juicios de residencias estudiados señalan que el corregidor concedía oficios de su casa, oficios ministeriales y algunas distinciones honoríficas a las élites indígenas. En cambio, en la corte regia se concedía negocios y gratificaciones de todo tipo sin excepción alguna. Por ello, nos toca analizar a continuación las repercusiones que tuvo el modelo cortesano en los corregimientos a través de la distribución de mercedes que el corregidor daba para la organización de su casa, para el nombramiento de sus ministros y para distinguir el rango social de las élites indígenas. Nos interesa examinar cómo los magistrados supieron maniobrar las normas a fin de legitimar prerrogativas no autorizadas.

\section{LA ORGANIZACIÓN DE LA CASA DEL CORREGIDOR}

La casa real en la Edad Moderna poseía dos significados. Era la residencia material del rey, dividida en áreas para los servidores domésticos y para los ministros que gobernaban el reino. También fue concebida como la familia extensa del monarca, pues allí residían no solo sus parientes consanguíneos, sino que además integraba al conjunto de criados (domésticos y gubernativos). Estos últimos pertenecían a la familia real porque habían sido agraciados por las mercedes que el rey les dio como padre de familia ${ }^{42}$. Estas ideas mostraron a la casa real como el núcleo del sistema de corte, puesto que desde allí partían las redes clientelares que reflejaron la organización política-social del reino ${ }^{43}$. Dicho parecer se fundamentó con la filosofía clásica a través de la oeconomica, que consideró el gobierno de la familia o casa como reflejo del gobierno de la ciudad ${ }^{44}$. A partir de ahí, se estableció que el ámbito familiar comenzaba a caracterizar al hombre como ser social, porque el pater familias se relacionaba con sus hijos y sirvientes a través de la concesión de mercedes ${ }^{45}$. Del mismo modo, tenía que aplicarse el gobierno de la casa a la administración de la monarquía. Ahí el rey como

39 Lazo y Tord, "Economía y sociedad en el Perú Colonial," 39.

40 CGPL, III, p. 199, Correspondencia del licenciado García de Castro a Felipe II, Lima, 1-X-1566; CGPL, III, p. 159; Correspondencia del licenciado García de Castro al Consejo de Indias, Lima, 26-II1566.

41 Tord, "El corregidor de indios en el Perú," 184.

42 Versteegen, Corte y Estado, 62-63.

${ }^{43}$ Hortal y Labrador, La Casa de Borgoña, 15.

${ }^{44}$ Hortal y Versteegen, Las ideas políticas y sociales en la Edad Moderna (Madrid: Síntesis, 2016), 10-11.

45 Ibídem, 76-78. 
pater familias tenía que redistribuir las mercedes a sus hijos o súbditos que le garantizasen un pleno servicio.

Una primera diferencia que se dio entre la casa real y la casa del corregidor estuvo en su denominación. Castillo de Bobadilla mencionó que una de las prerrogativas del magistrado era la de ser «aposentado en los palacios y casas reales, o públicas si las hubiere en la Ciudad o Pueblo de su Gobierno» ${ }^{46}$. No obstante, en los juicios de residencia y demás documentación estudiada no se ha encontrado el rótulo de "casa real" para nombrar a las casas de los magistrados. Las Leyes de Indias también han precisado tal convicción. En ninguna de sus ordenanzas se halló tal dignidad para los corregidores. A nivel provincial, los gobernadores eran los únicos oficiales reales que podrían y debían alojarse en las casas reales. Así se especificó cuando Felipe IV ordenó a los gobernadores «que habiten siempre en nuestras casas reales, y no truequen de vivienda con los vecinos» ${ }^{47}$. La segunda diferencia entre ambas casas estuvo en la exhibición del escudo de armas del monarca en la puerta principal. Esta medida se oficializó en 1583 cuando Felipe II mandó a la Audiencia de Lima que quitase las armas del virrey Francisco de Toledo en las puertas de las casas reales, audiencias, universidades y hospitales ${ }^{48}$. Esta cédula tampoco hizo mención al corregidor, por lo que no se presentaron dichos escudos en las puertas de sus casas. Sin embargo, estas cuestiones no le quitaron a la residencia del magistrado algunos rasgos comunes con la casa real de la corte como se verá más adelante.

Justamente una repercusión del modelo cortesano en la casa del corregidor fue la ubicación geográfica. La casa real tenía que levantarse en el punto central de los reinos y provincias para facilitar la articulación política de las jurisdicciones. De ese modo, la casa del corregidor se erigió en el centro político del corregimiento, es decir, el pueblo de indios que servía como sede de la administración. Estas capitales se caracterizaron por poseer la mayor población de la provincia, de ahí que fuese el lugar que otorgaba las mayores rentas ${ }^{49}$. Igualmente, la cabecera del corregimiento tenía que ver con la zona que brindaba la mejor accesibilidad de comunicación con los demás pueblos de la jurisdicción ${ }^{50}$. De esta manera, las casas de los corregidores tenían que estar en la zona más importante de la capital: la plaza mayor. En 1581, estas disposiciones quedaron aplicadas en la provincia del Cercado. Ahí el corregidor levantó su casa en un cuadrante de la plaza mayor ${ }^{51}$. Dicha medida facilitó la comunicación con los otros edificios principales que poseía la sede del corregimiento como la iglesia

\footnotetext{
46 Castillo de Bobadilla, Politica para corregidores, Lib. III, Cap. I, 7.

47 Recopilación de las Leyes de los Reinos de Indias (en adelante RLRI) (Madrid: Ediciones Cultura Hispánica, 1973[1681]), Lib. V, Cap. II, L. 48 f. 151v, Madrid a 17-VIII-1628.

${ }^{48}$ Diego de Encinas, Cedulario Indiano (Madrid: Ediciones Cultura Hispánica, 1944), vol. I, f. 261 262., Real Cédula al presidente y oidores de la Audiencia de Lima, San Lorenzo de El Escorial, 18-X1583.

${ }^{49}$ Castillo de Bobadilla, Política para corregidores, Lib. II, Cap. IX, 363; Juan de Solórzano y Pereyra, Politica indiana (Madrid: Matheo Sacristan, 1736[1647]), Lib. V, Cap. II, 261; Lohmann, El Corregidor de indios, 241.

${ }^{50}$ Castillo de Bobadilla, Política para corregidores, Lib. II, Cap. IX, 363

51 AHNM, Colección de Indias, 44, N.85, f. 4r., Relación de la ciudad de Lima por Antonio de León Pinelo, (1581).
} 
de doctrina y la casa de cabildo ${ }^{52}$. Por ende, aquellas residencias estuvieron enclavadas en sitios estratégicos que proporcionaron una mejor articulación del poder.

\subsection{El Ministro principal: el teniente de la provincia}

El oficial más importante que nombró el corregidor de indios en su casa fue el teniente de la provincia. Este ministro desempeñó diversas funciones políticas en el gobierno. Su naturaleza multifacética estuvo en que el teniente fue el asesor, consejero y delegado del corregidor en asuntos de materia judicial ${ }^{53}$. Como consejero y asesor, el teniente acompañaba siempre al corregidor en el tribunal cuando se celebraban los litigios, sentándose a su mano derecha y proporcionándole deliberaciones e informaciones útiles para la resolución de las sentencias. Por otro lado, el teniente actuó como delegado cuando el corregidor no podía despachar los negocios políticos y judiciales, ya sea por ausencia o enfermedad ${ }^{54}$. Así, el teniente se convertía - en ausencia del magistrado - en la primera potestad de la provincia. Por tales razones, al teniente de la provincia también se le conoció como teniente mayor, exhibiéndose como el ministro más poderoso del entorno del corregidor. Su labor como consejero, asesor y delegado hacía que todos los acuerdos y negocios pasasen por su mano y aprobación. Dichas características en las facultades del teniente mayor fueron comunes a la corte, pues fue una tradición que los ministros principales del rey tuviesen injerencia política en varios asuntos de la administración de los reinos. Además la denominación de «ministro» en la persona del teniente mayor fue siempre utilizada por el corregidor de indios para referirse a él. Así lo han manifestado todos los juicios de residencia estudiados, donde se tituló bajo el rótulo de «ministros y oficiales de su término ${ }^{55}$ no solo al teniente mayor, sino también a los demás criados que servían en el gobierno (tenientes de repartimiento, escribanos, alguaciles e intérpretes).

Estas dignidades al teniente de la provincia planteó otro posible rasgo común con la corte. Era una tradición que los primeros ministros del rey se ocupasen de la economía de la casa al ser mayordomos mayores ${ }^{56}$. En ese sentido, los tenientes mayores tuvieron la prerrogativa de llevar las cuentas para el mantenimiento de la casa del magistrado. En 1597, se dio el caso que precisó tal encargo en la provincia de Parinacochas. La residencia determinó que Diego Huamán, indio principal y teniente mayor del corregidor Francisco de Cepeda, «había abierto la caja comunal y se ha

52 Juan de Matienzo, Gobierno del Perú (Buenos Aires: Compañía Sudamericana de Billetes de Banco, 1910[1567]), 32.

53 Castillo de Bobadilla, Politica para corregidores, Lib. I, Cap. XII, 151-152; Albi, El corregidor en el municipio español, 232-234.

54 W. Borah, "Los auxiliares del gobernador provincial," en El gobierno provincial en la Nueva España 1570-1787 (México: Universidad Nacional Autónoma de México, 1985), 51; Antonio Muro, Lecciones de Historia del Derecho Hispano-Indiano (México: Miguel Ángel Porrúa, 1989), 220.

${ }^{55}$ Esta denominación aparece en los encabezados del primer folio de los expedientes de residencias a los corregidores de indios hallados en los repositorios peruanos y españoles.

${ }^{56}$ Gil González Dávila, Teatro de las grandezas de la villa de Madrid, Corte de los Reyes Católicos de España (Madrid, 1623), 313. 
gastado en las cosas de la morada del corregidor ${ }^{57}$. Esto representó que el teniente mayor podía saber cúales eran los materiales que la casa necesitaba para su ostentación y conservación. Esta deducción podría sostenerse con una merced que el corregidor dio a sus tenientes mayores: la tenencia de la llave de caja comunal. La misma residencia al corregidor de Parinacochas informó que «una llave de la caja de comunidad lo ha tenido la segunda persona del corregidor, Diego Huamán, indio principal» ${ }^{58}$. Caso similar se dio en la provincia de Jauja en 1591. Ahí el corregidor Martín de Mendoza dio su llave de caja a su teniente mayor Cristóbal Poma Ricra ${ }^{59}$. Sin embargo, estos hallazgos establecieron una diferencia con la corte: el teniente de la provincia no recibió el oficio de mayordomo mayor de la casa ni fue jefe de los criados domésticos. Ningún documento transfirió tal dignidad al principal ministro del corregidor, por lo que no existió este servicio cortesano. Si bien es cierto que el teniente pudo haberse encargado - en casos excepcionales - de las cuentas de la casa, eso no lo convirtió en el administrador general de la residencia. Dicho ministro se involucró más en las tareas gubernativas.

Los mecanismos de nombramiento que estableció del corregidor de indios para con su teniente mayor fueron diversos. Los lazos de amistad manifestaron una serie de relaciones personales que asimilaron rasgos comunes con el modelo cortesano. Un primer caso de nombramiento por amistad estuvo en la provincia de Condesuyos. En 1600, el corregidor Luis Ponce de León concedió el oficio a Miguel Farfán de los Godos como teniente mayor ${ }^{60}$. Esta relación se dio porque Miguel Farfán venía sirviendo fielmente al magistrado como teniente de los repartimientos de Andaguas, Vira y Pampacolca. Este caso evidenció una concentración de poder en la posesión del oficio, que se restringía a la red de clientelismo que más ayudaba al corregidor. Otro de los favorecidos por el corregidor Ponce de León fue Pedro Chacón Luna, quien también fue nombrado como teniente de Condesuyos habiendo sido antes teniente en el repartimiento de Chuquibamba ${ }^{61}$. Ambos casos resaltaron que los lazos de amistad con el corregidor conseguían un rápido ascenso en las carreras políticas de los que pedían las mercedes. Además tanto Miguel Farfán como Pedro Chacón disfrutaron la preeminencia de poseer las varas altas de justicia ${ }^{62}$, con lo cual se convirtieron en las autoridades que sentenciaban causas civiles y criminales cuando el corregidor se ausentaba.

El ascenso para ser teniente de la provincia se dio en el corregimiento de Canta. En 1593, se hizo relación que el corregidor Alonso de Armenta nombró a Martín Alonso del Villar y a Hernán Pérez como sus tenientes mayores. Ellos se habían

\footnotetext{
${ }^{57}$ Biblioteca Nacional del Perú (en adelante BNP), Mss. A236: Residencia a Francisco de Cepeda, corregidor de Parinacochas (1597), f. 17v, 19v.

${ }^{58}$ BNP, Mss. A236: Residencia a Francisco de Cepeda, corregidor de Parinacochas (1597), f. 17v, 19v.

59 Archivo General de la Nación Perú (en adelante AGNP), Real Audiencia, Residencias, Leg. 8, Exp. 21, fs. 28v-30v. Martín de Mendoza, corregidor de Jauja (1591).

${ }^{60}$ BNP, Mss. B1351: Diligencias hechas a Luis Ponce de León, corregidor de Condesuyos (1600), fs.51r, 55r.

${ }^{61}$ Ibídem., fs. 51r, 150r.

62 Ibídem., fs. 55r, 63r.
} 
desempeñado anteriormente como alguaciles del magistrado ${ }^{63}$. En 1591, se evidenció un caso similar en la provincia del Colesuyo y Moquegua. El corregidor Gaspar Moreno de los Ríos había nombrado a Antonio Delgado como su teniente mayor, quien antes había ejercido funciones como alguacil ${ }^{64}$. Asimismo, se hizo relación que el corregidor Gaspar Moreno había nombrado a muchos de sus alguaciles como tenientes en el repartimiento de Cochuna ${ }^{65}$. En 1593, en el corregimiento de Cotabambas también se estableció dicha práctica. Allí el corregidor Luis de Cárdenas Rojas ascendió a su escribano Bartolomé Jiménez al oficio de teniente mayor ${ }^{66}$. Estos casos expresaron la predilección del corregidor para nombrar a su primer oficial dentro de la clientela de ministros más leales. Ellos tenían que haber servido por un buen lapso de tiempo en un cargo o haber asistido al corregidor en varios oficios. Estos casos presentados sobre el ascenso para ser tenientes mayores mostraron una característica de filosofía cortesana. Según Alonso de Barros, todo cortesano encerraba dentro de sí una aspiración o pretensión de conseguir alguna riqueza o poder ${ }^{67}$. Este parecer tuvo repercusión en la escala y jerarquía de oficios que obtuvo el teniente mayor durante los años de servicio al corregidor. Por ello, el férreo servicio y fidelidad de los aspirantes a tenientes mayores en labores gubernativas y judiciales fue una característica para entender su amistad con el corregidor, que los llevaría luego a obtener la merced. Hay que agregar también que, en todos los casos mencionados, los corregidores no recibieron por parte de los virreyes ninguna comisión ni pedido especial para nombrar a los tenientes. De esta manera, estas relaciones se basaron en redes eminentemente personales. No existió provisiones de título en el nombramiento de los tenientes mayores, sino solamente el gozar del favor y deseo del corregidor para conseguir el oficio.

Para legitimar el nombramiento de tenientes mayores sin la autorización de los virreyes, los corregidores de indios apelaron a las mediaciones por costumbres. Así lo expresó el magistrado de Condesuyos, Luis Ponce de León, justificando su proceder de nombrar tenientes sin comisión porque «en todos los reinos y señoríos de su majestad, les es permitido a los corregidores que tengan tenientes y es costumbre antiquísima que no hace contradicción a las ordenanzas» ${ }^{68}$. En 1595, el corregidor de la provincia de Ica, Alonso Niño de Guzmán, también apeló a las costumbres para concederle a su teniente mayor, Diego de Figueroa, no solo el oficio, sino además la

${ }^{63}$ AGNP, Real Audiencia, Residencias, Leg. 11, Exp. 28, fs. 13r, 19r, 23v., Alonso de Armenta, corregidor de Canta (1593).

${ }^{64}$ BNP, Mss. A373: Residencia a Gaspar Moreno de los Ríos, corregidor del Colesuyo y Moquegua (1591), f. 75r, 83r-v.

${ }^{65}$ Ibídem., f. 75r.

66 AGNP, Real Audiencia, Residencias, Leg. 11, Exp. 27, fs. 25r, f. 31v-32r. Luis de Cárdenas Rojas, corregidor de Cotabambas (1593).

${ }^{67}$ José Martínez Millán, "Filosofía cortesana de Alonso de Barros (1587)," en Política, religión e inquisición en la España moderna. Homenaje a Joaquín Pérez. Villanueva, coords. José Martínez Millán, Pablo Fernández Albaladejo y V. Pinto Crespo (Madrid: Ediciones de la Universidad Autónoma de Madrid, 1996), 467.

${ }^{68}$ BNP, Mss. B1351: Diligencias hechas a Luis Ponce de León, corregidor de Condesuyos (1600), fs.141r-v, $144 \mathrm{v}$. 
preeminencia de llevar la vara alta de justicia para librar cualquier negocio que se presentase ${ }^{69}$. Castillo de Bobadilla defendió el nombramiento de tenientes por costumbres al señalar que era necesario conceder oficios a personas que tuviesen las mismas tradiciones en conductas políticas, sociales y culturales ${ }^{70}$. Por tal razón, se otorgaba el oficio de teniente a los allegados que compartían las mismas ambiciones del corregidor. De ahí que sobresaliese un segundo mecanismo en la entrega del cargo a personas que integraban su casa. Su amistad se entendía porque ambos tenían una similitud y complementariedad en intereses políticos.

Otra variante que surgió en los lazos de amistad estuvo en la relación corregidor de indios-curacas principales. En 1584, el magistrado de la provincia de Collaguas, Lucas de Cadaval, nombró por sus tenientes mayores a los curacas principales don Francisco y don Pedro Auca ${ }^{71}$. Ellos también recibieron la merced de administrar la justicia con vara alta por ausencia del corregidor. En 1580, se dio una misma circunstancia en la provincia de Lucanas. Allí el curaca principal de la provincia, don Francisco Cusi Maras, recibió la merced de ser teniente mayor por parte del corregidor Juan Manuel de Anaya ${ }^{72}$. Adicionalmente, se le entregó la merced de poseer vara alta de justicia, por lo que sentenció algunas causas ${ }^{73}$. Estas relaciones de amistad con el sector más poderoso de la sociedad indígena mostró el propósito del corregidor de indios para integrarlos como ministros principales de su casa. Así, la casa del corregidor estaba cumpliendo ser el núcleo articulador de su entorno político. Desde ahí se concedían los oficios de tenientes mayores a las élites indígenas. Dicha amistad se entendió gracias a dos factores. Primero, el servicio que los curacas principales e indios principales ofrecían al corregidor para el gobierno de la provincia, que expresó un primer acercamiento para integrarse en su casa. Prácticamente fue el punto de partida para el establecimiento de mediaciones personales por amistad entre el magistrado y los jefes étnicos ${ }^{74}$. Un servicio fundamental recayó en que los curacas y principales tenían que convocar a sus indios dispersados de sus comunidades para que se redujesen a menos pueblos ${ }^{75}$. En 1566, el curaca principal del valle de Jauja, Jerónimo Guacrapaucar, colaboró con el corregidor Juan de la Reinaga en la congregación de los indios en Hatun-Jauja ${ }^{76}$. Esto reflejó que el poder real dependía de la cooperación de las élites indígenas, dado que las autoridades reales carecían del

\footnotetext{
${ }^{69}$ BNP, Mss. A384: Residencia a Alonso Niño de Guzmán, corregidor de Ica (1595), f. 564r.

${ }^{70}$ Castillo de Bobadilla, Política para corregidores, Lib. I, Cap. XII, 151.

${ }^{71}$ AGNP, Real Audiencia, Residencias, Leg. 5, Exp. 9, f. 90r. Lucas de Cadaval, corregidor de Collaguas (1584).

${ }^{72}$ AGI, Escribanía de Cámara, 528A, fs. 78v, 100v, Residencia a Juan Manuel de Anaya, corregidor de Lucanas (1580).

${ }^{73}$ Ibíem., fs. 81r, 96v, Residencia a Juan Manuel de Anaya, corregidor de Lucanas (1580).

${ }^{74}$ Decreto del Concilio de Lima, 1583. Véase en García Yrigoyen, Santo Toribio, IV, 53; Colección Organización de la Iglesia y Órdenes Religiosas (en adelante COIOR), I, p. 278, Correspondencia de Toribio de Mogrovejo, arzobispo de Lima, a Felipe II, Lima, 30-IX-1583.

${ }^{75}$ CGPL, III, p. 116, Ordenanzas del licenciado Castro a los corregidores de indios (1565).

${ }^{76}$ Correspondencia del cabildo de indios de Hatun-Jauja al rey Felipe II, Jauja, 6-I-1566. Véase en Waldemar Espinoza, "Reducciones, pueblos y ciudades," en Pueblos y culturas de la Sierra Central del Perú, eds. D. Bonavia y R. Ravines (Lima: Cerro de Pasco Corporation, 1972), 107-109.
} 
acceso a los mecanismos sociales y políticos que posibilitasen su cohesión en la monarquía ${ }^{77}$. Por consiguiente, los curacas principales que cumplían con las expectativas del corregidor fueron los más propensos a convertirse en sus ministros. Esto le brindaba una permanencia en su posición social y una posibilidad de desarrollo ${ }^{78}$. Segundo, la merced al curaca por amistad fue resultado del reconocimiento político del corregidor al linaje y distinción que poseía el jefe étnico, que venía desde la fundación de sus parcialidades en tiempos prehispánicos ${ }^{79}$. Este rango los presentaba como los señores de indios, que correlacionó su distinción con el número de subordinados que lideraba ${ }^{80}$. Así, la amistad del corregidor con el curaca garantizaba la accesibilidad de disponer de la mano de obra indígena para cualquier asunto de trabajo que se necesitaba. El curaca podía convencer a sus indios para prestar sus servicios en la comunidad ${ }^{81}$. La amistad también posibilitó el control de los recursos de las cajas comunales para su uso en la casa del magistrado. Esto se mostró en 1597 cuando el corregidor de Parinacochas, Francisco de Cepeda, nombró al indio principal Diego Huamán como su teniente mayor y le entregó su llave de la caja de comunidad a fin de que obtuviese recursos para gastos suntuarios de su casa ${ }^{82}$.

Los lazos de parentesco y paisanaje también fueron determinantes en las mediaciones personales para el nombramiento del teniente mayor. En 1581, Pedro de Bustiza, quien era paisano del corregidor de Yucay - Pedro de Quiroz -, fue designado como teniente de la provincia. Además recibió la preeminencia de ser la autoridad judicial al tener la vara alta ${ }^{83}$. Esta práctica se daba con más certeza cuando el corregidor de indios se instalaba en su casa con algunos parientes consanguíneos. Así lo demostraron los juicios de residencia levantados en los corregimientos de Cotabambas y Jauja. En 1593, Sancho de Rojas, quien era tío del corregidor de Cotabambas - Luis de Cárdenas Rojas -, fue nombrado como teniente mayor y administró justicia con vara $a_{1 t a}{ }^{84}$. Por otro lado, el corregidor de Jauja, Martín de Mendoza, nombró como su

${ }^{77}$ Karen Spalding, "Resistencia y adaptación: el gobierno colonial y las élites nativas," Allpanchis XV (17-18) (1981), 5; Luis Miguel Glave y María Remy, Estructura agraria y vida rural en una región andina: Ollantaytambo entre los siglos XVI-XIX (Cusco: Bartolomé de las Casas, 1983), 11-13.

78 Polo, "El corregidor de Cusco," 134; Susan Ramírez, "La legitimidad de los curacas en los Andes durante los siglos XVI y XVII”, Boletín del Instituto Riva-Agüero 24 (1997): 471.

79 Susan Ramírez, "El concepto de 'comunidad' en el siglo XVI", en América bajo los Austrias: economía, cultura y sociedad, ed. H. Noejovich Ch. (Lima: Pontificia Universidad Católica del Perú, 2001), 183.

${ }^{80}$ Véase los estudios de Susan Ramírez, "El "dueño de indios": reflexiones sobre las consecuencias de cambios en las bases de poder del "curaca de los viejos antiguos" bajo los españoles en el Perú del siglo XVI," Hisla: Revista Latinoamericana de Historia Económica y Social 10 (1987): 39-41, "El concepto de “comunidad" en el siglo XVI,", 188;

81 Andrien, "El corregidor de indios," 515; Karen Spalding, "La otra cara de la reciprocidad," en Incas e indios cristianos. Elites indigenas e identidades cristianas en los Andes coloniales, ed. J. J Decoster (Cuzco: Centro de Estudios Bartolomé de las Casas, Instituto Francés de Estudios Andinos, 2002), 69; Susan Ramírez, El mundo al revés. Contactos y conflictos transculturales en el Perú del siglo XVI (Lima: Pontifica Universidad Católica del Perú, 2002), 300.

${ }^{82}$ BNP, Mss. A236: Residencia a Francisco de Cepeda, corregidor de Parinacochas (1597), f. 17v.

${ }^{83}$ BNP, Mss. A300: Residencia a Pedro de Quiroz, corregidor de Yucay (1581), f. 242v.

${ }^{84}$ AGNP, Real Audiencia, Residencias, Leg. 11, Exp. 27, fs. 25r, 31v-32r. Luis de Cárdenas Rojas, corregidor de Cotabambas (1593). 
teniente mayor a su pariente Jerónimo Pérez en 1591. Este lazo parental permitió una mayor facilidad para conceder la potestad de llevar la vara alta de justicia sin la provisión ni título del oficio ${ }^{85}$. Dichas relaciones de poder no estaban contempladas en la legislación indiana, dado que se prohibía que los corregidores designasen a ministros y oficiales que fuesen sus parientes hasta el cuarto grado ${ }^{86}$. Sin embargo, dicha práctica fue entendida porque formaba parte de una costumbre que buscaba dotar de una homogeneidad y unidad a los miembros de su casa, quienes formaban parte de la familia del corregidor. De ahí que los vínculos de consanguinidad se comprendieron como la extensión de las mercedes, de forma exclusiva, en los clanes familiares del magistrado como principio organizador de un sistema patrimonial de gobierno $^{87}$. Aquí el servicio para conseguir la merced pasó a un segundo plano.

\subsection{Los criados domésticos}

La casa del corregidor de indios presentó una organización de espacios y oficios con una determinada funcionalidad y variedad. Los oficios estaban organizados y divididos en dos grandes secciones: los criados interiores (realizaban únicamente tareas dentro de la casa) y los criados exteriores (realizaban labores afuera de la residencia para su mantenimiento). Así lo manifestó el fraile Bernardino de Cárdenas en 1601, afirmando que existía una diversidad de indios criados que acompañaban al corregidor en su residencia ${ }^{88}$. Ahora, es preciso analizar cómo pudo repercutir la corte en esta organización de oficios domésticos y cuáles podrían ser las diferencias.

El grupo de criados interiores se dividió en cinco espacios: el aposento, la cocina, las caballerizas, la portería y el salón principal ${ }^{89}$. En el aposento cabe resaltar el servicio de las indias acompañantes en el lecho del corregidor. En 1593, la residencia al corregidor de indios de Cotabambas, Luis de Cárdenas Rojas, evidenció que el magistrado llevaba por la noche a un grupo de indias a su dormitorio para la cópula carnal. Asimismo, se mostró que dicho corregidor sentía mucho apego y pasión por Paula, una de sus indias acompañantes, quien estuvo gestando un hijo de él ${ }^{90}$. En la cocina estuvieron la india cocinera, la india fregadera ${ }^{91}$ (que se ocupaba no solo de lavar los platos, sino también de la limpieza diaria de la cocina), la india chichera y la india panadera. Esta proliferación de indias, tanto en el aposento como en la cocina, se debió a que ellas buscaban conseguir comida sin paga y poseer indios mitayos para su servicio

\footnotetext{
85 AGNP, Real Audiencia, Residencias, Leg. 8, Exp. 21, fs. 199r, 204r, 209r. Martín de Mendoza, corregidor de Jauja (1591).

${ }^{86}$ RLRI, Lib. V, Cap. II, L. 45.

${ }^{87}$ Alexandre Coello de la Rosa, Espacios de exclusión, espacios de poder: el Cercado de Lima (1568-1606) (Lima: Pontificia Universidad Católica del Perú, 2006), 124, 167.

88 BNE, Mss. 3198: Memorial y relación de cosas muy graves... del reino del Perú de fray Bernardino de Cárdenas (1601), f. 70r-v.

${ }^{89}$ Ibídem., f. 70r.

${ }^{90}$ AGNP, Real Audiencia, Residencias, Leg. 11, Exp. 27, f. 135v., Luis de Cárdenas Rojas, corregidor de Cotabambas (1593).

${ }_{91}$ BNE, Mss. 3198: Memorial y relación de cosas muy graves... del reino del Perú de fray Bernardino de Cárdenas (1601), f. 70r.
} 
personal. Guamán Poma fue claro al respecto al mencionar que lo que movía a las indias para ser mancebas y criadas del corregidor tenía que ver con la búsqueda de riqueza $^{92}$. En ese sentido, hubo una repercusión de la corte porque todo cortesano planificaba la obtención de su fortuna mediante la liberalidad, adulación, diligencia y trabajo ${ }^{93}$. De esta forma, estos oficios significaron no una estigmatización de baja estirpe, sino fueron una fuente de mercedes para la distinción social.

El criado de la caballeriza desempeñó una labor muy particular y especial. Él fue el encargado de alistar al conjunto de equinos para la movilización del corregidor de indios. Por tal razón, fue un oficio que distinguía el rango social, pues de ellos dependía la comunicación del corregidor con los términos de la provincia. A dicho criado se le denominó indio caballerizo o caballucamaio ${ }^{94}$, quien además se encargaba de un celoso cuidado del caballo del magistrado. En 1580, se reflejó su labor fidelísima en el corregimiento de Cañete. El indio principal Juan Quivi, quien era caballerizo del corregidor Hernán Vázquez de Puga, se resistió a darle el caballo del magistrado al curaca principal de Carabayllo, don Pedro Quispichumbi ${ }^{95}$. El noble indígena aseveraba que el corregidor le había concedido merced para que montase su caballo. Sin embargo, Juan Quivi desconocía la orden del corregidor, por lo que se rehusaba a no entregar el equino. La jerarquía social que existió entre el curaca principal y el indio principal no fue impedimento para que el criado cumpliese su misión. Mientras gozase de la cercanía del magistrado y viviese en su casa, la movilidad social de su estatus estuvo asegurada. Otro factor a resaltar fue que el corregidor de indios concedió uno de sus oficios domésticos más importantes a un indio de la nobleza baja, lo cual demostró que este sector no fue excluido del entorno político del magistrado.

Para cerrar el conjunto de criados internos cabe mencionar, primero, al indio portero $^{96}$. Él se encargaba de la vigilancia diaria del recinto. Segundo, los indios músicos, quienes eran los llamados a ejercer las labores de entretenimiento en el salón principal de la casa. Un caso especial de su participación se dio en el corregimiento de Cotabambas. En 1593, el corregidor Luis de Cárdenas Rojas fue con sus indios músicos a la casa de la india Paula para cantarle una serenata. Los indios músicos usaron sus guitarras y el corregidor entonaba la letra de las canciones ${ }^{97}$. Se había mencionado anteriormente que dicha india era acompañante del corregidor Cárdenas. Por tanto, la serenata fue entendida como una merced que otorgó el magistrado a su india para que ella siempre le sirviese en su aposento. Aquí podría haberse dado un servicio palatino a la criada, pues fue típico que las rondallas fueran una honra

92 Guamán Poma, Nueva corónica y buen gobierno, 383, 386.

93 Martínez Millán, "Filosofía cortesana," 468.

${ }^{94}$ BNE, Mss. 3198: Memorial y relación de cosas muy graves... del reino del Perú de fray Bernardino de Cárdenas (1601), f. 70r.

${ }^{95}$ BNP, Mss. A537: Residencia a Hernán Vázquez de Puga, corregidor de Cañete (1580), f. 26r-v.

${ }^{96}$ BNE, Mss. 3198: Memorial y relación de cosas muy graves... del reino del Perú de fray Bernardino de Cárdenas (1601), f. 70r.

${ }_{97}$ AGNP, Real Audiencia, Residencias, Leg. 11, Exp. 27, f. 135v. Luis de Cárdenas Rojas, corregidor de Cotabambas (1593). 
cortesana en las casas reales. Lamentablemente, para este hecho no hay más documentación que pudiese arrojar más luces sobre dicho servicio y corroborarlo.

El grupo de criados externos fue muy variado. Los servidores más importantes dentro de este séquito fueron los indios que llevaban las correspondencias y los indios que realizaban los mandados ${ }^{98}$. Gracias a un expediente de residencia, se determinó que el indio mandadero cumplía el servicio de realizar cualquier disposición que el corregidor de indios necesitaba en materia política, económica y judicial. Por tal razón, este oficio fue entregado a los indios principales, ya que estos eran los nexos entre los curacas y los indios comunes. El caso que ejemplificó esta relación personal se dio en la provincia de Cañete. En 1580, el corregidor Hernán Vázquez de Puga encargó a don Martín, quien era alguacil e indio principal de Surco, que llevase la llave del magistrado para que abriese la caja de comunidad de Maranga y le llevase el dinero que había en ella ${ }^{99}$. Asimismo, don Martín tenía que ir hasta el repartimiento de Magdalena, en donde los indios principales de allí iban a recibir el dinero para llevarlo al pueblo de Surco $^{100}$. En ese sentido, existió una red de indios mensajeros diseminados en zonas estratégicas de la provincia. Hay que destacar el mecanismo de nombramiento basado en la amistad entre el corregidor y los indios principales. Ellos representaron ser los candidatos para obtener la merced, puesto que servían por mucho tiempo como alguaciles de sus parcialidades y conocían a la perfección toda la red de caminos que permitía la ejecución del mandado con más rapidez. Otro grupo de beneficiados para ser indios mandaderos fueron los hijos de los curacas principales. En 1599, el corregidor de Cajatambo, Alonso de Mendoza, encargó a don Rodrigo, hijo del curaca principal de la provincia, don Juan, a llevar su llave de la caja comunal para que su teniente Juan Clavero la abriese ${ }^{101}$. Un factor a considerar fue que don Rodrigo era hermano del indio intérprete del corregidor ${ }^{102}$. Estas relaciones personales pusieron en práctica una red de clientelaje familiar de las élites indígenas para ingresar al entorno del corregidor. Tanto el intérprete como el curaca aprovecharon su distinción en la casa del magistrado para promover a sus parientes en la concesión de mercedes.

El grupo de criados externos se cerró con cinco oficiales más. Todos ellos abastecían en alimentos a la cocina de la casa. El indio nevero enfriaba el agua y transportaba los bloques de hielo. Los indios fruteros recolectaban toda clase de frutos en las chacras. Labor parecida cumplieron los indios pescadores. El indio guarda mulas se encargaba del pastoreo de dichos animales en los páramos. Por último, los indios encargados de conseguir los alimentos necesarios para la cocina ${ }^{103}$. Pero, la relación de

${ }^{98}$ BNE, Mss. 3198: Memorial y relación de cosas muy graves... del reino del Perú de fray Bernardino de Cárdenas (1601), f. 70v. $71 \mathrm{r}$.

${ }_{99}$ BNP, Mss. A537: Residencia a Hernán Vázquez de Puga, corregidor de Cañete (1580), fs. 46r-v, 47v, 54r,

${ }^{100}$ Ibídem., f. 71v.

101 AGNP, Real Audiencia, Residencias, Leg. 16, Exp. 43, f. 10v-11r, 17v. Alonso de Mendoza, corregidor de Cajatambo (1599).

102 Ibídem., f. 10v-11r, Alonso de Mendoza, corregidor de Cajatambo (1599).

103 BNE, Mss. 3198: Memorial y relación de cosas muy graves... del reino del Perú de fray Bernardino de Cárdenas (1601), f. 70v. 
estos criados mereció el cuestionamiento y crítica de los doctrineros. Ellos acusaban al corregidor de entorpecer su labor evangelizadora, ya que los indios permanecían muy ocupados en las tareas domésticas ${ }^{104}$. Asimismo, denunciaban al magistrado por cometer abusos y opresiones a dichos indios. Según el fraile Bernardino de Cárdenas, los indios «no recibían paga, ni un pedazo de pan para su comida porque esta se la traen sus pobres mujeres ${ }^{105}$. Sin embargo, la veracidad de las quejas de los clérigos debe tomarse con cierto cuidado, dado que tienen que entenderse dentro del contexto político de los corregimientos andinos del siglo XVI ${ }^{106}$.

La relación de criados domésticos presentó algunos rasgos comunes con la corte. Primero, la casa tuvo una división jerárquica de criados tanto para el servicio interno como el externo. El corregidor contaba con un grupo de criados que abastecían su casa con todo tipo de alimentos; al mismo tiempo con criados para cualquier clase de mandados. Así, en el caso de los criados internos, se representó un servicio palatino con las indias del aposento y los indios músicos. Ellos se dedicaban exclusivamente a la diversión y entretenimiento del corregidor. Segundo, el servicio en la casa fijó parámetros en la integración de las élites andinas en el entorno del magistrado. Fue el caso del caballucamaio y del mandadero, quienes fueron indios principales. Esto demostró que la casa del corregidor siguió funcionando como núcleo de articulación política entre la sede de gobierno y las demás parcialidades de la provincia tal como lo hacía la casa real en la corte. No obstante, la relación de criados también señaló amplias diferencias con la corte. Quizá la más importante fue la distribución de espacios para los criados. Dichos ámbitos fueron los mismos que podría tener cualquier casa principal en el Perú virreinal. Tanto el aposento, la cocina, la caballeriza y el salón principal se presentaban en toda casa solariega de familias importantes, por lo que no fue un rasgo cortesano. Otra diferencia se encontró en la no presencia de oficios domésticos de larga tradición cortesana como el sumiller de corps, (encargado del cuidado del aposento del rey), el mayordomo mayor (jefe de los criados y administrador de la economía de la casa) y el gentilhombre (jefe de la guardia real), que no existieron en la casa del corregidor. Dichos criados - tomando el ejemplo de la corte virreinal del Perú - fueron los que ostentaron la más alta confianza del vicesoberano. A estos se les sumó el maestresala (encargado del servicio del comedor),

${ }^{104}$ COIOR, I, p. 278, Correspondencia del arzobispo de Lima, Toribio de Mogrovejo, a Felipe II, Lima, 30-IX-1583.

105 BNE, Mss. 3198: Memorial y relación de cosas muy graves... del reino del Perú de fray Bernardino de Cárdenas (1601), f. 70v.

${ }^{106} \mathrm{La}$ introducción de los corregidores quitó poder político a los clérigos en los pueblos de indios. Esta rivalidad se alimentó más con las medidas que dio García de Castro a los magistrados en 1565. En su mayoría, las ordenanzas se centraban en la supervisión de los doctrineros para tareas únicamente religiosas. Además se fijó un control político por parte de los corregidores al exigirles que les diesen los libros de bautismos para evitar alteraciones del padrón tributario. Por tales razones, los clérigos pudieron haber exagerado en sus quejas. Para más detalles de este enfrentamiento véase en CGPL, III, pp. 117 120, Ordenanzas del licenciado Lope García de Castro a los corregidores de indios del Perú (1565); Assadourian, "Los señores étnicos y los corregidores de indios," 245-248. Sobre el control de los libros bautismales por parte del corregidor véase Robles, "La efigie del rey en el corregidor de indios," 92-93. 
pajes y lacayos (asistentes del maestresala en la mesa), los capellanes y confesores (encargados del culto religioso) ${ }^{107}$.

\subsection{Los demás ministros de gobierno}

\subsubsection{Los tenientes de repartimiento}

El corregidor de indios siempre necesitó de un grupo de ministros que lo ayudasen a desplegar su poder en los distintos repartimientos que componían su provincia. Esa fue la principal justificación que sustentaron los corregidores para legitimar el nombramiento de tenientes para cada repartimiento. Estos ministros tenían la labor de ejecutar diversas tareas que el magistrado le mandaba ${ }^{108}$. Dichos asuntos fueron la recolección de las tasas del tributo, el envío de los mitayos, supervisión de obras públicas y la administración de justicia en casos especiales. Por eso, los tenientes de repartimiento fueron también denominados como jueces de comisión, pues realizaban negocios particulares con la autorización del corregidor. Así lo expresaron los corregidores Juan Manuel de Anaya y Antonio de Heredia en 1580. Ellos decían que era primordial que se dejasen en cada cabecera de sus provincias a jueces de comisión o tenientes para que ellos juntasen la tasa, hiciesen chacras y enviasen a los mitayos, dado que era amplio el territorio que administraban ${ }^{109}$.

En 1587, los pareceres que apelaban a la costumbre para el beneficio de los tenientes de repartimiento fueron apoyados también por el virrey Conde de Villar. Él aseveró que era imposible que un corregidor de indios pudiese ejercer la jurisdicción civil y criminal en todas las zonas de la provincia ${ }^{110}$. Así, el virrey autorizó al corregidor de Cañete, Francisco Quiñones, que nombrase a tenientes en cada repartimiento de la provincia ${ }^{111}$. Estas razones aseguraron una dispersión en la designación de tenientes de repartimiento a gusto y deseo del magistrado. En ese sentido, sus mecanismos de nombramiento se basaron en las mediaciones personales por vínculos de amistad y parentesco.

Los lazos de amistad para la concesión del oficio de teniente de repartimiento se dieron, en primer lugar, en la provincia de Cotabambas. En 1593, el corregidor Luis de Cárdenas Rojas nombró al mestizo Gaspar Gómez, quien era su alguacil, como su

107 Para un análisis más detallado de los criados domésticos en la casa real de la corte virreinal del Perú, véase Eduardo Torres Arancivia, Corte de virreyes. El entorno del poder en el Perú del siglo XVII (Lima: Pontificia Universidad Católica del Perú, Instituto Riva-Agüero, 2014), 81-86.

${ }_{108}$ Castillo de Bobadilla, Política para corregidores, Lib. II, Cap. XX, 779, Hevia, Curia Philipica, 19.

109 AGI, Escribanía de Cámara, 528A, f. 153v. Residencia a Juan Manuel de Anaya, corregidor de la provincia de Lucanas (1580); AGNP, Real Audiencia, Residencias, Leg. 1, Exp. 2, f. 195v. Antonio de Heredia, corregidor de Camaná (1580).

${ }^{110}$ CGPL, X, p. 268, Correspondencia del virrey Conde de Villar a Felipe II, Lima, 12-IV-1587.

111 Relación al rey que hizo el virrey Conde de Villar sobre el gobierno del Perú, Callao, 25-V-1586, en Lewis Hanke, Los Virreyes españoles en América durante el gobierno de la Casa de Austria: Perú (Madrid: Atlas, 1978), I, 199. 
teniente en los repartimientos de Chaquira y Yanaguaras ${ }^{112}$. Aquí se observaron dos características. Primero, se concedió la merced a ministros que venían sirviendo al corregidor de indios por un tiempo prolongado. De la misma manera se dio en la provincia de Yucay cuando el corregidor Pedro de Quiroz nombró a su escribano Antonio de Porras como teniente de los repartimientos de Laris ${ }^{113}$ y Huayabamba ${ }^{114}$, poseyendo vara alta de justicia en 1581. Esto fomentó un ascenso en las carreras políticas de Gaspar Gómez y Antonio de Porras, quienes habían servido como ministros del magistrado anteriormente. Dicho ascenso favoreció que los ministros se entornillasen en el oficio dos veces, puesto que ambos - luego de acabar su labor pasaron a otro repartimiento con la misma preeminencia de poseer la vara alta de justicia ${ }^{115}$. Estos casos demostraron la pretensión cortesana expresada en la búsqueda de riqueza.

Segundo, la entrega del oficio estuvo en el factor racial. Un mestizo como Gaspar Gómez llegó a ocupar el segundo oficio más importante del entorno del corregidor. La estigmatización negativa que la sociedad virreinal vio en los mestizos tuvo un valor relativo dentro de un sistema basado en relaciones personales. Lo que primaba eran los lazos de amistad por el servicio ofrecido a la figura real, que hizo a Gaspar Gómez merecedor del favor del corregidor de Cotabambas. En 1595, se evidenció un caso similar en el corregimiento de Ica. El magistrado Alonso Niño de Guzmán nombró a su amigo, el negro liberto Pedro Trujillano, como teniente de los valles de Nazca y le dio merced para ejercer la vara alta de justicia ${ }^{116}$. Pedro Trujillano se había desempeñado como criado doméstico en la casa del corregidor, por lo que este caso demostró que la merced para ser teniente de repartimiento estaba también reservada para los humildes criados que habían forjado una carrera de servicio y lealtad al magistrado. Así lo dejó entrever Guamán Poma al expresar que el corregidor tuvo como criados a «algunos mestizos, mulatos, o de los dichos negros, o de ellos sus propios yanaconas, y salen muy ricos a costa de los pobres indios» ${ }^{117}$. La causa de su ascenso político-económico se dio porque fueron honrados como ministros de gobierno tal como lo demostraron los juicios de residencia anteriores.

Los casos analizados no fueron los únicos para el corregimiento de Ica. En 1581, el corregidor Diego de Valera creó una red de clientelaje múltiple, concediendo el oficio para dos o más servidores en un mismo repartimiento. En Nazca fueron nombrados Alonso Benítez, quien ejerció como juez de comisión en las pagas de los indios para la tasa tributaria ${ }^{118}$, Alonso Pérez de Vivero, Antonio Carrillo y Francisco

112 AGNP, Real Audiencia, Residencias, Leg. 11, Exp. 27, fs. 80r, 113r, 136r. Luis de Cárdenas Rojas, corregidor de Cotabambas (1593).

113 BNP, Mss. A300: Residencia a Pedro de Quiroz, corregidor de Yucay (1581). f. 180v-181v, 183r.

${ }^{114}$ Ibídem., f. 182v.

115 AGNP, Real Audiencia, Residencias, Leg. 11, Exp. 27, fs. 113r, 136r. Luis de Cárdenas Rojas, corregidor de Cotabambas (1593).

${ }_{116}$ BNP, Mss. A384: Residencia a Alonso Niño de Guzmán, corregidor de Ica (1595), f. 563r.

117 Guamán Poma, Nueva corónica y buen gobierno, 383.

118 AGNP, Real Audiencia, Residencias, Leg. 2, Exp. 4, f. 115r. Diego de Valera, corregidor de Ica (1581). 
de $A r a o z{ }^{119}$. En el repartimiento de Chincha fue favorecido con el oficio Pedro Caballero, y en Pisco fue nombrado Jorge Pérez ${ }^{120}$. En 1580, se dio otro caso más en las relaciones de poder por amistad en la provincia de Cañete. Ahí el corregidor Hernán Vázquez de Puga dio merced a sus amigos Jerónimo Ruiz y Diego de Ibarra para ser tenientes de los repartimientos de Lunahuaná y Cañete respectivamente ${ }^{121}$. Los agraciados, tanto en Ica como en Cañete, sirvieron al corregidor en el alguacilazgo o escribanía de su repartimiento. Otra característica en la red de clientelaje múltiple se apreció en que los favorecidos concentraron la sucesión del oficio en dos o más repartimientos. En 1597, se vio en el caso de Diego Zapata, quien recibió la merced del corregidor de Parinacochas, Francisco de Cepeda, para ser teniente del repartimiento de Pomatambo, y después teniente de Guaynacota ${ }^{122}$.

Las élites indígenas no quedaron exentas en los lazos de amistad para la concesión del oficio. El corregidor de indios entabló mediaciones personales con los curacas principales e indios principales con el objeto de que ellos fuesen sus delegados en los grupos étnicos. De este modo, las élites indígenas fue uno de los sectores favoritos del magistrado para concederles el cargo, puesto que conocían a la perfección las parcialidades, pachacas y guarangas de las que eran jefes. Esto quedó manifestado cuando el gobernador García de Castro autorizó a sus corregidores de indios que nombrasen a los curacas o indios principales de los repartimientos para que fuesen sus segundas personas durante las visitas a la provincia ${ }^{123}$. Un primer caso que demostró dicha práctica se dio en Lucanas. En 1580, el corregidor Juan Manuel de Anaya nombró al curaca principal de Cabana, don Francisco, como teniente del repartimiento de Andamarca. Además le otorgó la merced de poseer la vara alta de justicia, con lo que administró y sentenció algunos pleitos ${ }^{124}$. En 1593, el corregidor de Cotabambas, Luis de Cárdenas Rojas, creó una red clientelar con curacas e indios principales. Juan Poma Quispe, curaca principal de Cotabambas, fue nombrado como teniente en Collurqui; mientras que Francisco Chochocas, principal de Pomacóndor, fue agraciado como teniente en Chaquira ${ }^{125}$. En 1580, se evidenció dicha relación amistosa con el indio principal don Agustín, quien fue honrado por el corregidor de Camaná, Antonio de Heredia, con el oficio de teniente del repartimiento de Caravelí y le concedió poder para administrar los negocios y pleitos ${ }^{126}$. El colaboracionismo de las autoridades indígenas con el corregidor para el aprovechamiento de los recursos del repartimiento

${ }^{119}$ Ibídem., f. 112r. Diego de Valera, corregidor de Ica (1581).

120 Ibídem.

121 BNP, Mss. A537: Residencia a Hernán Vázquez de Puga, corregidor de Cañete (1580), f. 115r-v.

${ }^{122}$ AGNP, Real Audiencia, Residencias, Leg. 14, Exp. 38, f. 528r, 533v. Francisco de Cepeda, corregidor de Parinacochas (1597).

${ }^{123}$ BNE, Mss. 3043: Provisión del licenciado García de Castro a los corregidores de indios, Lima, 26-IX-1565, f. 15.

124 AGI, Escribanía de Cámara, 528A, fs. 81r, 96v. Residencia a Juan Manuel de Anaya, corregidor de Lucanas (1580).

125 AGNP, Real Audiencia, Residencias, Leg. 11, Exp. 27, f. 138v-139r. Luis de Cárdenas Rojas, corregidor de Cotabambas (1593).

${ }^{126}$ AGNP, Real Audiencia, Residencias, Leg. 1, Exp. 2, f. 85v. Antonio de Heredia, corregidor de Camaná (1580). 
fue premiado. El magistrado les reconoció no solo su servicio, sino también su posición social al entregarles el tenientazgo con facultades gubernativas y judiciales.

Los lazos parentales también caracterizaron las vías para conceder la merced en el oficio de teniente de repartimiento. Este mecanismo se mostró en el corregimiento de Camaná. En 1580, el corregidor Antonio de Heredia nombró a sus parientes en primer grado, Julián Chávez y Francisco Muñoz, como tenientes de los repartimientos de Quilca y Majes respectivamente ${ }^{127}$. Otro caso se dio en el corregimiento de Parinacochas. En 1597, el corregidor Francisco de Cepeda nombró a su pariente Manuel de Zurita como teniente del repartimiento de Parinacochas ${ }^{128}$. La residencia mostró que no necesariamente importaba el vínculo sanguíneo con el corregidor. Bastaba solo un parentesco lejano para ser considerado en la clientela. Tener parientes que eran ministros de gobierno implicaba que se crease una extensa red de clientelaje familiar y amical. Estos tenientes serían los promotores para que sus amigos y parientes, que vivían en el repartimiento, lograsen el favor real.

Estos mecanismos de nombramiento a los tenientes de repartimiento ocasionaron que la concesión de dicho oficio se exagerase en su número, llegando a tener un corregidor de indios entre diez o doce tenientes en su provincia ${ }^{129}$. En los casos analizados se presentó un doble juego del corregidor de indios. Al poder solo nombrar a dicho teniente con licencia y mandado expreso del virre ${ }^{130}$, los magistrados idearon una fórmula común para entregar el oficio bajo el matiz de ser juez de comisión. Pero, al llegar al repartimiento, el juez de comisión se proclamaba como teniente del corregidor y libraba negocios políticos y jurídicos más allá de los estipulados. Así, él no presentaba su provisión del oficio. Estas circunstancias mostraron una característica común con la corte. Los importantes cargos no necesitaron de acuerdos contractuales con el corregidor para ocupar el oficio. El único requisito era contar con su favor para ser ministro. Esto manifestó una red de relaciones de poder no institucionales tal como lo tenía la corte. Sin embargo, el nombramiento de estos tenientes denotó también rasgos que lo alejaron de una influencia cortesana. Una cuestión radicó en el poder delegado del corregidor para designar a sus tenientes. Las mercedes entregadas tenían que ejecutarse bajo el amparo del virrey, por lo que le quitó su carácter principesco. Otra diferencia tuvo que ver con la alteración de la legislación para dar el oficio. Al actuar forzando las instrucciones que le mandaban los virreyes, ellos ejercieron un poder despótico.

\subsubsection{Los escribanos}

El escribano desempeñaba un papel arduo, ya que llevaba la cuenta de toda actividad política trazada en la provincia. Así, el corregidor de indios necesitaba

\footnotetext{
127 Ibídem., fs. 91r, 100v. Antonio de Heredia, corregidor de Camaná (1580).

128 AGNP, Real Audiencia, Residencias, Leg. 14, Exp. 38, f. 557v. Francisco de Cepeda, corregidor de Parinacochas (1597).

${ }^{129}$ Guamán Poma, Nueva crónica y buen gobierno, 378, 385.

${ }^{130}$ Luis de Velasco, "Ordenanzas para corregidores (1601)", Revista del Archivo Nacional del Perú 17(2) (1944[1601]), 131; RLRI, Lib. V, Cap. II, L. 42.
} 
nombrar a personas de su confianza en dicho ministerio. Por tal razón, se legitimó su nombramiento sin ningún tipo de comisiones ni autorizaciones. En 1595, este parecer fue compartido por el virrey García Hurtado de Mendoza, quien ordenó a los corregidores que nombrasen escribanos a su entera satisfacción para que ellos se encargasen de las revisitas de tributos y residencias ${ }^{131}$. Esta medida fue aprovechada por los magistrados. Ellos no solo aumentaron el nombramiento de escribanos sin licencia alguna, sino también les dieron altísimos sueldos provenientes de las cajas comunales de la jurisdicción. Allí jugó un papel medular las relaciones personales que se analizarán a continuación.

Los mecanismos para obtener el oficio de escribano se dio, principalmente, por amistad. El primer caso se dio en la provincia del Colesuyo y Moquegua en 1591. Ahí el corregidor Gaspar Moreno de los Ríos nombró a tres de sus amigos como escribanos sin comisión alguna. Ellos fueron Pedro Miguel Moreno, Juan Escudero y Gonzalo López ${ }^{132}$. El siguiente caso se dio en el corregimiento de Cañete. En 1580, el magistrado Hernán Vázquez de Puga nombró a dos de sus amigos como escribanos, quienes fueron Pedro de Ayllón ${ }^{133}$ y Cristóbal Méndez ${ }^{134}$. Ellos gozaron de una distinción social, pues acompañaron en todo momento y a todas partes al corregidor durante la revisita de tributos ${ }^{135}$. Estos casos evidenciaron una arraigada frecuencia en la concesión de la merced. En cada provincia existieron dos o más escribanos, por lo que fue el segundo oficio que más veces entregó el corregidor, luego del cargo de teniente de repartimiento. Su pedido recurrente se debió a que el oficio gozó de magnífico salario. Este parecer fue señalado por el contador mayor del Perú virreinal en el siglo XVII, Francisco López de Caravantes. Él hizo relación que en el corregimiento del Ica, el escribano de Pisco, Agustín Mejía de Mora ganó 2.500 ducados ${ }^{136}$. Mismo parecer fue informado por Guamán Poma, quien acusó a los corregidores de dar a sus escribanos un salario de 1.000 pesos que se extraían de la caja de comunidad ${ }^{137}$. Esto se demostró en la provincia de Jauja, en donde el corregidor dispuso que su escribano ganase 300 pesos a costa de los bienes comunales ${ }^{138}$. En 1593, tal actividad lucrativa fue precisada por Gabriel Martínez, escribano del corregidor de Cotabambas, Luis de Cárdenas Rojas, quien decía «que había obtenido el oficio para ganar dinero y no para perderlo». Por tal razón, llevaba su salario a costa de los indios litigantes ${ }^{139}$.

${ }^{131}$ CGPL, XIII, p. 230, Correspondencia del virrey García Hurtado de Mendoza a Felipe II, Lima, 20-I-1595.

132 BNP, Mss. A373: Residencia a Gaspar Moreno de los Ríos, corregidor del Colesuyo y Moquegua (1591), fs. $82 \mathrm{v}-83 \mathrm{r}$.

133 BNP, Mss. A537: Residencia a Hernán Vázquez de Puga, corregidor de Cañete (1580), f. 14r.

134 Ibídem., f. 115 r.

135 Ibídem., fs. 14r, 115r.

${ }^{136}$ Francisco López de Caravantes, Noticia general del Perú. (Madrid: Atlas, 1986), II, 61.

137 Guamán Poma, Nueva crónica y buen gobierno, 389-390.

${ }^{138}$ López de Caravantes, Noticia general del Perú, II, 63.

139 AGNP, Real Audiencia, Residencias, Leg. 11, Exp. 27, f. 171v. Luis de Cárdenas Rojas, corregidor de Cotabambas (1593). 
Por ende, el ingreso del escribano en el entorno del corregidor aseguraba un enriquecimiento inmediato. El interés por obtener este oficio se debió más a sus fines lucrativos. Pero, al mismo tiempo reflejó ser un puesto central para hacer carrera política. El agraciado tenía todas las disposiciones para escalar oficios a fin de conseguir el tenientazgo mayor o de los repartimientos. Dicha característica acercó el ministerio del escribano con la filosofía cortesana, pues él buscaba riqueza a base del trabajo de sus diligencias encomendadas.

\subsubsection{Los indios intérpretes}

$\mathrm{Al}$ ser el oficio de intérprete un ministerio especial, la Corona le reconoció una distinción social con calidades y prerrogativas, así como el goce de salario como cualquier oficial real ${ }^{140}$. Por cada doce preguntas del interrogatorio que el intérprete traducía al castellano durante los procesos judiciales, recibía dos tomines ${ }^{141}$. Fue por esta razón que el oficio era altamente lucrativo, puesto que la gran mayoría de los expedientes sobrepasaba las doce preguntas. Así, este beneficio fue aprovechado por los indios intérpretes, quienes a costa de los indios litigantes cobraban sus salarios. Otro privilegio que se les dio fue el hacer ceremonia de juramento de su cargo ante la autoridad competente ${ }^{142}$.

Los beneficiados para obtener dicho cargo fueron los indios yanaconas del corregidor, es decir, los indios del común que se desempeñaban como criados domésticos en su casa. Así quedó plasmado en la provincia de Canta. En 1593, el corregidor Alonso de Armenta nombró a su indio yanacona Pedro Pichu como su intérprete ${ }^{143}$. Otro segundo grupo de beneficiados para ser indios intérpretes fueron los hijos de los curacas principales que servían al corregidor como guardianes de las cajas de comunidad. Este caso se mostró en 1599 cuando el corregidor de Cajatambo, Alonso de Mendoza, dio el oficio al hijo del curaca principal de la provincia, don Juan ${ }^{144}$. El jefe étnico no solo fue promotor del ingreso de su familia en el entorno del corregidor. También fue el intermediario en el ascenso de su hijo como oficial gubernativo. Esto le aseguró la permanencia de su reconocimiento político por parte del corregidor. Gracias al curaca, la casa del magistrado articulaba el poder con servidores indígenas de toda la provincia.

Un segundo aspecto a analizar estuvo en la merced de inmunidad concedida a Pedro Pichu. Él había golpeado al alcalde indígena de Canta, Juan Carvae, y riñó con el curaca de Atavillos, Juan Sacha, durante un altercado que surgió en una casa de juegos. Esto no fue causa para que el indio intérprete fuese castigado y encerrado. El corregidor Armenta nunca lo castigó ni lo encerró. Por el contrario, mandó azotar al

\footnotetext{
140 RLRI, Lib. II, Cap. XXIX, L. 1; Guamán Poma, Nueva crónica y buen gobierno, 383.

${ }^{141}$ Encinas, Cedulario Indiano, vol. II, f. 369, Ordenanza a la Real Audiencia de Lima (1563).

142 Ibídem, f. 368, Ordenanza a la Real Audiencia de Lima (1563).

143 AGNP, Real Audiencia, Residencias, Leg. 11, Exp. 28, f. 58v. Alonso de Armenta, corregidor de Canta (1593).

144 AGNP, Real Audiencia, Residencias, Leg. 16, Exp. 43, f. 10v-11r. Alonso de Mendoza, corregidor de Cajatambo (1599).
} 
alcalde Carvae y al curaca de Atavillos ${ }^{145}$ por haber ocasionado el escándalo ${ }^{146}$. Dicha circunstancia plasmó el comportamiento del corregidor como un verdadero pater familias. El magistrado no solo daba merced en el cargo a su indio favorito, sino que además le brindaba protección ante cualquier eventualidad criminal que lo perjudicase. La legislación que dio el virrey Francisco de Toledo precisaba que los indios comunes que se emborrachasen tenían que recibir cien azotes por parte del corregidor ${ }^{147}$. De esta manera, la posesión de un oficio de gobierno aseguraba la movilidad social de Pedro Pichu, quien dejó de ser indio común para ser parte de la élite andina. Él disfrutó de inmunidades, preeminencias y honras que tuvo cualquier oficio cortesano. Así, el corregidor ofrecía inmunidad a todos los miembros que formaban parte de su casa sin importar su jerarquía social de procedencia.

\section{CONCLUSIÓN}

La documentación analizada logró demostrar que el sistema de corte tuvo algunas repercusiones en el entorno político de los corregimientos de indios. Primero, la calidad del corregidor como cabeza de su provincia. Él gozó de un poder jurisdiccional con dominio y mando político sobre todas las personas de su circunscripción. Esta potestad le permitía conceder las mercedes reales como oficios domésticos de su casa, oficios de gobierno y preeminencias a las élites indígenas. Esto garantizó que el corregidor tuviese a un séquito de ministros bajo su administración, que lo asistían en su casa y en el gobierno provincial. Segundo, su casa se convirtió en el núcleo de articulación de poder por todas las zonas de la provincia, puesto que incorporó a las élites indígenas. Ellos ostentaron ser sus ministros más poderosos. Un tercer rasgo se reflejó en la numerosa organización de criados domésticos con espacios delimitados para el servicio. Existió un séquito de criados encargados exclusivamente para tareas de abastecimiento, comunicación y asistencia, así como un séquito de servidores para labores dentro de la residencia Un cuarto elemento fue la filosofía cortesana de la pretensión. Los criados y ministros hacían carrera política de méritos y servicios para ascender a oficios más prestigiosos. Su búsqueda de fortuna les confirmaba altísimos salarios y distinción social. Por último, las relaciones de poder personales entre el corregidor y sus allegados significó la presencia de una organización política-social que tenía como elementos a su casa, el cuerpo de criados y ministros y los personajes gratificados.

Sin embargo, esto no evidenció que los corregidores constituyesen una corte. Las diferencias radicaron, principalmente, en la carencia del carácter principesco en el corregidor. Si bien es cierto que él poseyó un poder jurisdiccional, este le fue limitado por las ordenanzas que le mandaba el virrey. Al ser una autoridad delegada, esto

145 AGNP, Real Audiencia, Residencias, Leg. 11, Exp. 28, f. 92r. Alonso de Armenta, corregidor de Canta (1593).

146 Ibídem., f. 58v. Alonso de Armenta, corregidor de Canta (1593).

${ }^{147}$ Francisco de Toledo, "Ordenanzas para los indios de todos los departamentos y pueblos de este reino," en Relaciones de los virreyes y audiencias que han gobernado el Perú (Lima: Imprenta del Estado, vol. I, 1867[1578]), 166-167. 
repercutió en sus facultades para entregar las mercedes. Dichas prerrogativas que daba el corregidor a sus allegados tenían que ajustarse a lo establecido por las disposiciones reales. Él no podía realizar cualquier tipo de merced sin excepción alguna. En algunos casos, se dio que el corregidor maniobraba la legislación para conceder las mercedes, pero nunca sobrepasó los límites señalados. Por eso, las instrucciones reales no distinguieron a la casa del corregidor como casa real.

La no presencia del carácter principesco en el corregidor determinó tres diferencias más. Las áreas domésticas fueron las mismas que tenía una casa solariega en la sociedad virreinal como los aposentos, el salón principal, la caballeriza y la cocina. Segundo, la relación de criados domésticos no determinó la presencia de oficiales con arraigo cortesano como el mayordomo mayor, el sumiller de corps y los gentilhombres. Si bien es cierto que sus criados fueron numerosos y tuvieron una división de tareas, esto no logró asimilar la organización política-social que tenía una casa real. Por último, los ministros más importantes no alcanzaron a copar la esfera privada y pública del corregidor al mismo tiempo. La documentación no ha demostrado que los tenientes mayores ni los tenientes de repartimiento ni los escribanos ejerciesen oficios domésticos. 


\section{FUENTES Y BIBLIOGRAFÍA}

\section{Fuentes documentales}

Archivo General de Indias

Lima, 569, L.11; Lima, 270; Escribanía de Cámara, 528A.

Archivo Histórico Nacional. Madrid

Colección de Indias, 44, N.85

Biblioteca Nacional de España

Mss. 3043; Mss. 3198

Arcbivo General de la Nación. Perú

Real Audiencia /Residencias: (Leg. 1, Exp. 2); (Leg. 2, Exp. 4); (Leg. 5, Exp. 9); (Leg. 8, Exp. 21); (Leg. 11, Exp. 27); (Leg. 11, Exp. 28); (Leg. 14, Exp. 38); (Leg. 16, Exp. 43).

\section{Biblioteca Nacional del Perú}

Mss. A236; Mss. A300; Mss. A373; Mss. A384; Mss. A537; Mss. B1351

\section{Fuentes impresas}

Castillo de Bobadilla, Jerónimo. Política para corregidores, y señores de vasallos, en tiempo de paz, y de guerra, y prelados en lo espiritual, y temporal. (Madrid: Imprenta de Joaquín de Ibarra, 1759[1597]).

Concejo Provincial de Trujillo. Actas de Cabildo de Trujillo II: 1566-1571. (Lima, 1969).

Diccionario de la lengua castellana en que se explica el verdadero sentido de las voces, su naturaleza y calidad, con las phrases o modos de hablar, los proverbios o refranes, y otras cosas convenientes al uso de la lengua. (Madrid: Imprenta de Francisco del Hierro, vol. 2, 1729).

Encinas, Diego. Cedulario Indiano. Madrid: Ediciones Cultura Hispánica, 4 vols., (1944). 
Espinoza, Waldemar. "Reducciones, pueblos y ciudades". En Pueblos y culturas de la Sierra Central del Perú, editado por D. Bonavia y R. Ravines, 101-113. (Lima: Cerro de Pasco Corporation, 1972).

García Yrigoyen, C. Santo Toribio: inéditos del Archivo de Sevilla. (Lima: Imprenta y Librería de San Pedro, vol. IV, 1906).

Góngora, Bartolomé. El corregidor sagaz: abisos, y documentos morales para los que lo fueren. (Sevilla: Sociedad de Bibliófilos Españoles, 1960[1656]).

González Dávila, Gil. Teatro de las grandezas de la villa de Madrid, Corte de los Reyes Católicos de España. (Madrid, 1623).

Guamán Poma, Felipe. Nueva corónica y buen gobierno. (México: Fondo de Cultura Económica, 1993).

Guardiola, Lorenzo. El Corregidor perfecto y Juez: (Madrid: Imprenta y Librería de López, 1785).

Hanke, Lewis. Los Virreyes españoles en América durante el gobierno de la Casa de Austria: Perú. (Madrid: Atlas, vol. I, 1978).

Hevia, Juan. Curia Philipica. (Madrid: Oficina de Ramón Ruíz, 1797).

Levillier, Roberto. Organización de la Iglesia y órdenes religiosas en el Virreinato del Perú en el siglo XVI. (Madrid: Sucesores de Rivadeneyra, vol. I, 1919).

Levillier, Roberto. Gobernantes del Perú: cartas y papeles siglo XVI. (Madrid: Sucesores de Rivadeneyra, vols. III-X-XIII, 1921-1926).

López de Caravantes, Francisco. Noticia general del Perú. (Madrid: Atlas, vol. II, 1986).

Matienzo, Juan. Gobierno del Perú. (Buenos Aires: Compañía Sudamericana de Billetes de Banco, 1910[1567]).

Maurtúa, Víctor. Juicio de Limites entre el Perú y Bolivia: prueba peruana presentada al gobierno de la República Argentina. (Barcelona: Henrich y Cía, vol. I, 1906).

Recopilación de las Leyes de los Reynos de las Indias. (Madrid: Ediciones Cultura Hispánica, 1973[1681]).

Solórzano y Pereyra, Juan. Política Indiana. (Madrid: Matheo Sacristan, 1736[1647]). 
Toledo, Francisco. "Ordenanzas para los indios de todos los departamentos y pueblos de este reino". En Relaciones de los virreyes y audiencias que han gobernado el Perú, 156219. (Lima: Imprenta del Estado, vol. I, 1867[1578]).

Velasco, Luis. "Ordenanzas para corregidores (1601)". Revista del Archivo Nacional del Perú 17, 2 (1944[1601]): 125-143.

\section{Referencias bibliográficas}

Albi, Fernando. El corregidor en el municipio español bajo la monarquía absoluta. (Madrid: Instituto de Estudios de Administración Local, 1943).

Álvarez-Ossorio, Antonio. "Corte y cortesanos en la Monarquía de España". En Educare il corpo. Educare la parola: nella trattatisdica del Rinascimento, editado por G. Patrizi y A. Quondam, 297-314, (1997).

Andrien, K. J., "El corregidor de indios, la corrupción y el Estado virreinal en el Perú (1580-1630)". Revista de Historia Económica 4(3) (1986): 493-520. https://doi.org/10.1017/S0212610900014634

Assadourian, C. S. "Los señores étnicos y los corregidores de indios". En Transiciones hacia el sistema colonial andino, 244-260. (Lima: El Colegio de México, 1994).

Borah, W. "Los auxiliares del gobernador provincial". En El gobierno provincial en la Nueva España 1570-1787, 51-64. (México: Universidad Nacional Autónoma de México, 1985).

Castañeda, Carlos E. "The Corregidor in Spanish Colonial Administration". The Hispanic American Historical Review 9(4) (1929): 446-470. https://doi.org/10.2307/2506753

Coello de la Rosa, Alexandre. Espacios de exclusión, espacios de poder: el Cercado de Lima (1568-1606). (Lima: Pontificia Universidad Católica del Perú, 2006).

Cook, N. D. "The Corregidores of the Colca Valley, Peru: Imperial Administration in an Andean Region". Anuario de Estudios Americanos 60(2) (2003): 413-439.

https://doi.org/10.3989/aeamer.2003.v60.i2.153

De la Puente, José Carlos. Andean cosmopolitans: seeking justice and reward at the Spanish royal court. (Austin: University of Texas Press, 2018). 
García-Gallo, Alfonso. "Alcaldes mayores y corregidores en Indias". En Estudios de Historia del Derecho Indiano, 714-736. (Madrid: Instituto Nacional de Estudios Jurídicos, 1972).

Glave, Luis Miguel, y María Remy. Estructura agraria y vida rural en una región andina: Ollantaytambo entre los siglos XVI-XIX. (Cusco: Bartolomé de las Casas, 1983).

Hortal, J. E., y F. Labrador. La Casa de Borgoña: la Casa del rey de España. (Leuven: Leuven University Press, 2014).

Hortal, J. E., y Gijs Versteegen. Las ideas politicas y sociales en la Edad Moderna. (Madrid: Síntesis, 2016).

Lazo, Carlos, y Javier Tord. "Economía y Sociedad en el Perú Colonial (Movimiento social)". En Historia del Perú, 39-50. (Lima: Juan Mejía Baca, vol. V, 1980).

Lohmann, Guillermo. El Corregidor de indios en el Perú bajo los Austrias. ( $2^{\circ}$ ed.). (Lima: Pontificia Universidad Católica del Perú, 2001).

Mariluz Urquijo, José. El agente de la administración pública en Indias. (Buenos Aires: Instituto Internacional de Historia del Derecho Indiano, 1998).

Martínez Millán, José. Instituciones y elites de poder en la Monarquia Hispana durante el siglo XVI. (Madrid: Ediciones de la Universidad Autónoma de Madrid, 1992).

Martínez Millán, José. "Filosofía cortesana de Alonso de Barros (1587)”. En Política, religión e inquisición en la España moderna. Homenaje a Joaquín Pérez. Villanueva, coordinado por José Martínez Millán, Pablo Fernández Albaladejo y V. Pinto Crespo, 461-481. (Madrid: Ediciones de la Universidad Autónoma de Madrid, 1996).

Martínez Millán, José. “Introducción”. En La Monarquía de Felipe II: la Casa del Rey, 1751. Madrid: Fundación Mapfre, vol. I, 2005.

Molina, Carlos. "Gobernaciones, alcaldías mayores y corregimientos en el reino de Guatemala". Anuario de Estudios Americanos 17 (1958): 105-132.

Moreno, Alfredo. El corregidor de indios y la economía peruana del siglo XVIII (Los repartos forzosos de mercancias). (Madrid: Consejo Superior de Investigaciones Científicas, 1977).

Muro, Antonio. Lecciones de Historia del Derecho Hispano-Indiano. (México: Miguel Ángel Porrúa, 1989). 
Noack, Karoline. "El orden colonial inventado: estrategias y actitudes de los caciques e indígenas de Cajamarca, sierra norte del Perú, S. XVI". Cuadernos de Historia 1 (2002): 5-14.

Polo, Adolfo. "El corregidor de Cusco y el Estado colonial. Siglos XVI-XVII". Tesis de Maestría en Historia, Pontificia Universidad Católica del Perú, 2010.

Ramírez, Susan. 'El 'dueño de indios': reflexiones sobre las consecuencias de cambios en las bases de poder del 'curaca de los viejos antiguos' bajo los españoles en el Perú del siglo XVI”. Hisla: Revista Latinoamericana de Historia Económica y Social 10 (1987): 39-66.

Ramírez, Susan. "La legitimidad de los curacas en los Andes durante los siglos XVI y XVII". Boletin del Instituto Riva-Agüero 24 (1997): 467-492.

Ramírez, Susan. "El concepto de 'comunidad' en el siglo XVI". En América bajo los Austrias: economía, cultura y sociedad, editado por H. Noejovich Ch., 181-188. (Lima: Pontificia Universidad Católica del Perú, 2001).

Ramírez, Susan. El mundo al revés. Contactos y conflictos transculturales en el Perú del siglo XVI. (Lima: Pontificia Universidad Católica del Perú, 2002).

Rivero, Manuel. "Court Studies in the Spanish World". En The Court in Europe, editado por M. Fantoni, 135-147. (Roma: Bulzoni Editore, 2012).

Robles, Javier. "Dos aspectos claves en la política del virrey Marqués de Cañete. Autoridades y tasación en el ordenamiento de los indios, Perú 1555-1560". En Actas del I Congreso de Historia y Cultura, compilado por E. Rosario, C. Castillo y M. Palacios, 9-30. (Lima: Seminario de Historia Rural Andina, Universidad Nacional Mayor de San Marcos, 2014).

Robles, Javier. "La efigie del rey en el corregidor de indios: cultura política y poder real de un magistrado en el proceso de consolidación del Estado virreinal durante el régimen del gobernador Lope García de Castro, Perú 1564-1569”. Tesis de Licenciatura en Historia, Universidad Nacional Mayor de San Marcos, 2015.

http://cybertesis.unmsm.edu.pe/handle/cybertesis/4556 (Consultado el 25 de mayo del 2018).

Ruiz Guiñazú, Enrique. La magistratura indiana. (Buenos Aires: Universidad de Buenos Aires, 1916).

Spalding, Karen. De indio a campesino. Cambios en la estructura social del Perú colonial. (Lima: Instituto de Estudios Peruanos, 1974). 
Spalding, Karen. "Resistencia y adaptación: el gobierno colonial y las élites nativas". Alpanchis XV, 17-18, (1981): 5-19.

Spalding, Karen. "La otra cara de la reciprocidad". En Incas e indios cristianos. Elites indígenas e identidades cristianas en los Andes coloniales, editado por J. J Decoster, 6175. (Cuzco: Bartolomé de las Casas, Instituto Francés de Estudios Andinos, 2002). https://doi.org/10.4000/books.ifea.4078

Suñe, Beatriz. "El corregidor del valle de Guatemala: una institución española para el control de la población indígena". Revista de la Universidad Complutense 117 (1979): 153-168.

Tord, Javier. "El corregidor de indios del Perú: comercio y tributos". Historia y Cultura 8 (1974): 173-207.

Torres Arancivia, Eduardo. Corte de virreyes. El entorno del poder en el Perú del siglo XVII, (Lima: Pontificia Universidad Católica del Perú, Instituto Riva-Agüero, 2014).

Versteegen, Gijs. Corte y Estado en la historiografia liberal: un cambio de paradigma. (Madrid: Polifemo, 2015).

Zuloaga, Marina. La conquista negociada: guarangas, autoridades locales e imperio en Huaylas, Perú (1532-1610). (Lima: Instituto Francés de Estudios Andinos, Instituto de Estudios Peruanos, 2012). https://doi.org/10.4000/books.ifea.6541

Recibido: 6 de junio de 2019 Aprobado: 12 de noviembre de 2019 